\title{
Review of sensing technologies for measuring powder density variations during pharmaceutical solid dosage form manufacturing
}

\author{
S. Stranzinger ${ }^{1}$, D. Mark1 ${ }^{2,3}$, J. G. Khinast ${ }^{1,4}$, A. Paudel ${ }^{1,4 *}$ \\ ${ }^{1}$ Research Center Pharmaceutical Engineering (RCPE) GmbH, Graz, Austria \\ ${ }^{2}$ Strathclyde Institute of Pharmacy \& Biomedical Sciences, University of Strathclyde, Glasgow, \\ UK \\ ${ }^{3}$ Future Continuous Manufacturing and Advanced Crystallisation Research Hub, University of \\ Strathclyde, Glasgow, UK \\ ${ }^{4}$ Institute for Process and Particle Engineering, Graz University of Technology, Graz, Austria
}

\begin{abstract}
Oral solid dosage forms, the most widely used pharmaceutical products, are typically manufactured through a series of processes that transform a blend of drug and excipient particles into a densified product with consistent quality attributes. While the densification of powder during processing is crucial and directly impacts the quality of the drug product, there is still scarcity of non-destructive and fast sensor systems that provide access to the powder density at critical process stages. This review discusses methods for monitoring density variations of particulate matter by describing their principles and presenting application examples. The techniques discussed range from common in-line methods such as near-infrared spectroscopy, acoustic emission and ultrasonic methods as well as techniques with potential to be more frequently applied in a pharmaceutical manufacturing line, i.e. terahertz spectroscopy and imaging, microwave technique, electrical tomography and X-ray based methods. This review also compares these techniques in terms of measurement and data processing time, resolution and its ability to be integrated in a process.
\end{abstract}

Keywords: Quality control, process analytical technology (PAT), process monitoring, sensing technologies, powder bulk density

*Corresponding author:

Amrit Paudel

Research Center Pharmaceutical Engineering GmbH

Inffeldgasse 13/II, 8010 Graz, Austria

Email: amrit.paudel@rcpe.at

Phone: +43 31687330912

Fax: +43 3168731030912 


\section{Contents}

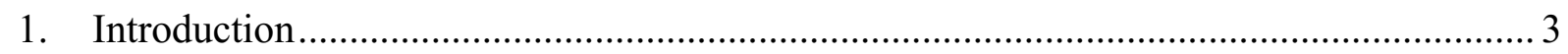

1.2 Powder density variations and related product performance ...................................... 4

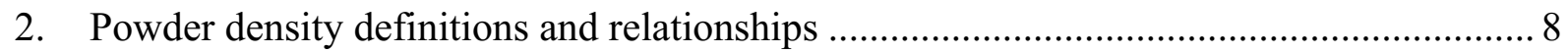

3. Monitoring powder density variations in the framework of FDA's PAT initiative ........... 10

4. Technologies for monitoring of powder density variations ............................................ 11

$4.1 \quad$ Near-infrared spectroscopy and chemical imaging ................................................. 13

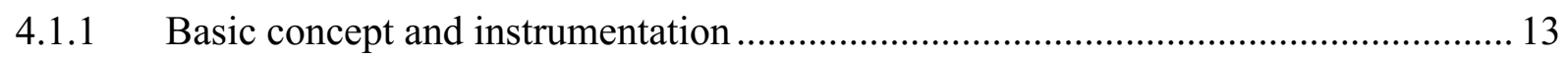

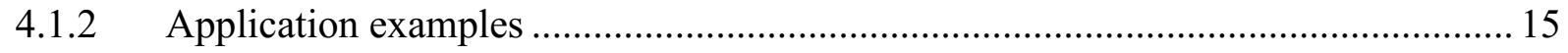

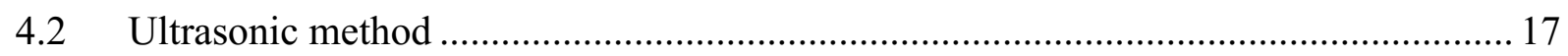

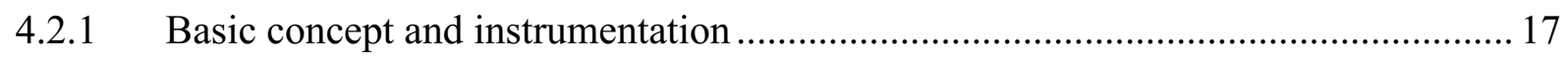

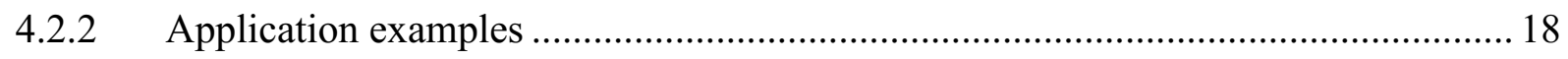

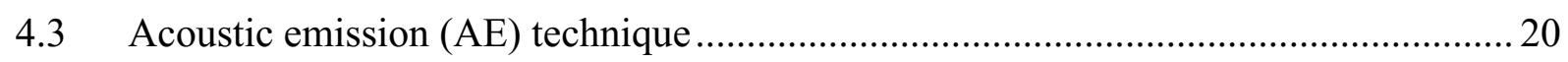

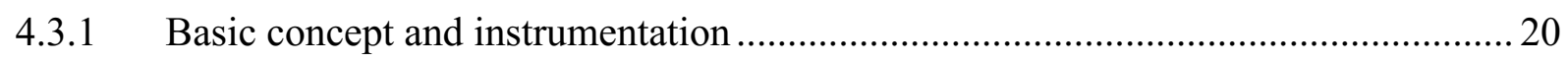

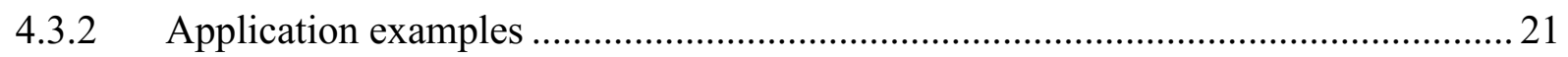

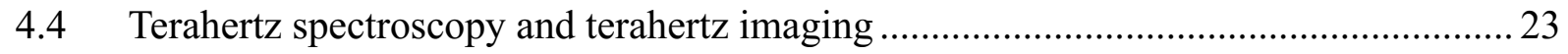

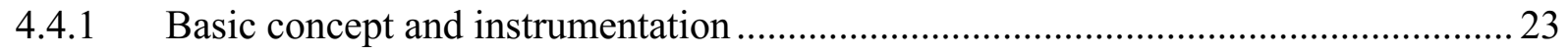

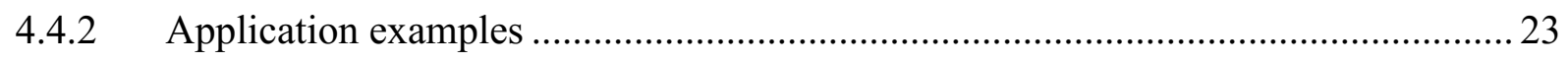

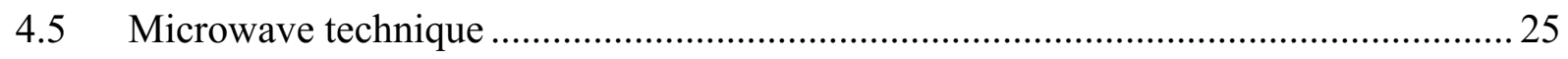

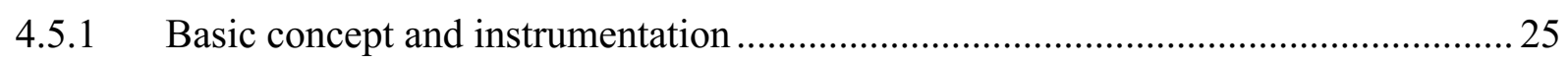

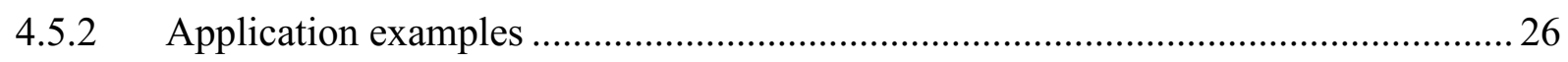

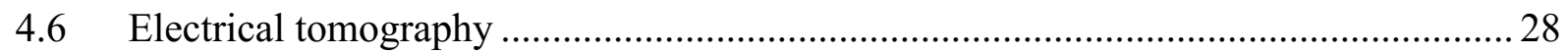

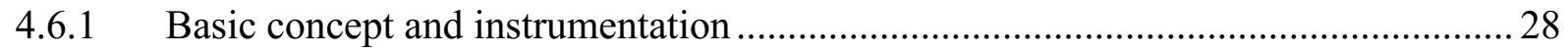

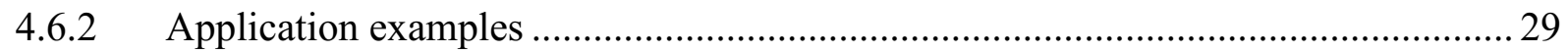

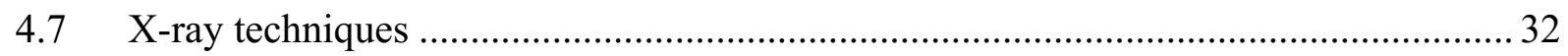

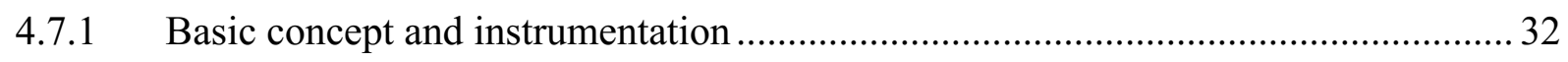

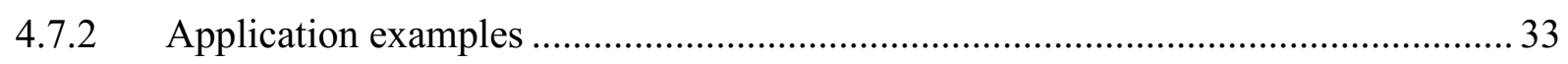

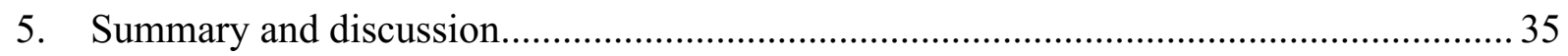

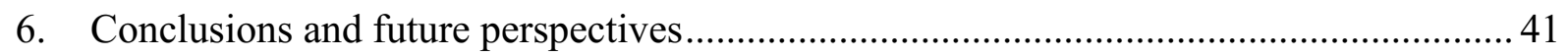

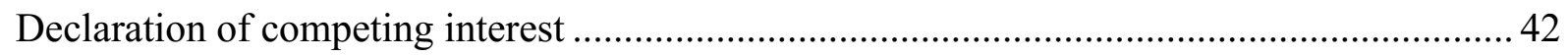

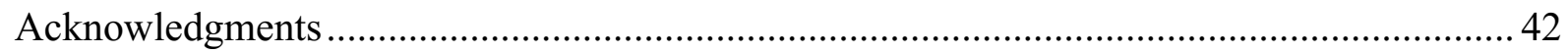

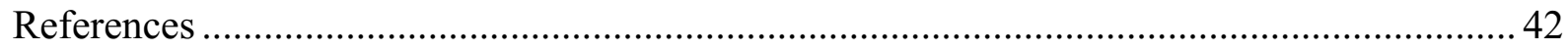




\section{Introduction}

In the pharmaceutical industry the majority of pharmaceuticals are initially solids in the form of a powder combined with excipients to improve manufacturability and performance of the final drug product (e.g., tablets and capsules). One of the most critical bulk properties of the drug and excipient materials that can impact the operation (e.g., flow and compaction properties) of the pharmaceutical processes and the product's quality (e.g. dissolution) is the powder density. The density of powder is typically quantified as bulk, tapped and relative density, where the relative density of powdered pharmaceutical materials generally increases during manufacturing [1]. Powder particle size and shape distributions and interactions between particles and the processing equipment introduce density heterogeneities in the powder and gradients in the final dosage form [2]. This is undesired, yet cannot be completely avoided.

Many pharmaceutical unit operations are based on a volumetric operation (e.g. feeding, capsule filling, tableting) and hence the quality of the processed material is highly sensitive to the powder density of the material entering the unit operation as well as to variations of the density during processing. Table 1 presents an overview of the significance of the impact of a variation in powder density on the final product quality for the major conventional pharmaceutical soliddosage-form processing routes (tableting and capsule filling) and unit operations. The powder density of processes identified as medium $(++)$ and high impact $(+++)$ operations requires close attention in the development of a control strategy. This table can thus inform the control strategy in terms of the relevance of implementing a process analytical technology (PAT) for monitoring of density variations during manufacturing. 
Table 1: Impact of a variation in powder density on the final product quality. The scoring is related to the significance of the impact of a variation in powder density on the final product quality and indicated as "+" for low impact "++" for medium impact and "+++" high impact.

\begin{tabular}{|c|c|c|c|c|c|c|c|}
\hline & Method & Feeding & Blending & $\begin{array}{l}\text { Granulati } \\
\text { on } \\
(D G / W G)\end{array}$ & $\begin{array}{l}\text { Milling } \\
(D G) / \\
\text { Drying } \\
(W G)\end{array}$ & Blending & $\begin{array}{l}\text { Compress } \\
\text { ion }\end{array}$ \\
\hline \multirow{4}{*}{$\frac{\frac{n}{0}}{\frac{0}{0}}$} & Direct compression & +++ & ++ & n.a. & n.a. & ++ & ++ \\
\hline & Dry granulation & +++ & ++ & ++ & +++ & + & ++ \\
\hline & Wet granulation & +++ & ++ & +++ & + & + & ++ \\
\hline & & Blending & Feeding & Layering & Dosing & Filling & \\
\hline \multirow{5}{*}{$\frac{\mathscr{e}}{\frac{\mathscr{\theta}}{\sigma}}$} & Auger filling & ++ & ++ & n.a. & n.a. & ++ & \\
\hline & $\begin{array}{l}\text { Vibration assisted } \\
\text { filling (Microdosing) }\end{array}$ & ++ & ++ & n.a. & n.a. & ++ & \\
\hline & $\begin{array}{l}\text { Dosator nozzle } \\
\text { filling }\end{array}$ & ++ & ++ & ++ & +++ & + & \\
\hline & $\begin{array}{l}\text { Tamp/dosing disc } \\
\text { filling }\end{array}$ & ++ & ++ & + & +++ & + & \\
\hline & $\begin{array}{l}\text { Vacuum drum } \\
\text { filling/dosing wheel }\end{array}$ & ++ & ++ & + & + & + & \\
\hline
\end{tabular}

$\mathrm{DG}=$ Dry granulation, $\mathrm{WG}=$ Wet granulation, $\mathrm{n} . \mathrm{a} .=$ not applicable

\subsection{Powder density variations and related product performance}

The manufacturing of major conventional pharmaceutical solid oral dosage forms (tablets and capsules) involves several processes ranging from powder transfer, feeding, blending to filling, dosing and compression. Many physical responses of powders, granules and compacts, such as powder flowability and tensile strength, are determined largely by their absolute and relative densities [1]. Powder density changes during processing may influence the functioning of pharmaceutical products, whereas the extent of impact depends on the processing route/unit operation. An overview of the effect of powder and drug product density on critical quality 
attributes (CQAs) and manufacturability characteristics is provided in Figure 1. This schematic representation indicates the following powder density to product quality relationships:

- Powder density affects the transport and processing of powder (e.g., flowability and segregation tendency) and impacts CQAs of the drug product, such as disintegration and content uniformity.

- The differences in density of the powder components can induce segregation [3] and also impacts the flowability of powder [1]. Flowability particularly influences the processability and in many cases drives the choice of excipients and manufacturing process (e.g. direct compression vs granulation) [4]. The flow of powders during manufacturing dictates the quality of the product in terms of its weight and content uniformity [4]. Segregation can also impact processability, but can also have an effect on content uniformity of the drug product [5]. CQAs of the drug product are strongly impacted by the powder density of intermediate products (e.g. granules or powder blend) [6].

The points above clearly highlight the impact of powder and drug product density on the critical quality attributes (CQAs) and manufacturability characteristics. The importance of powder density for prediction of product developability and processability was also introduced by Leane et al. [7], who developed a drug product Manufacturing Classification System (MCS) for oral solid dosage forms. The MCS aims to assist formulators and engineers to rationally select a manufacturing process for a drug product. Another concept for determining whether powders (API or excipient) are suitable for a specific manufacturing route (i.e., direct compression), is the SeDeM expert system [8]. Again, powder density is listed as key assessment parameter. 


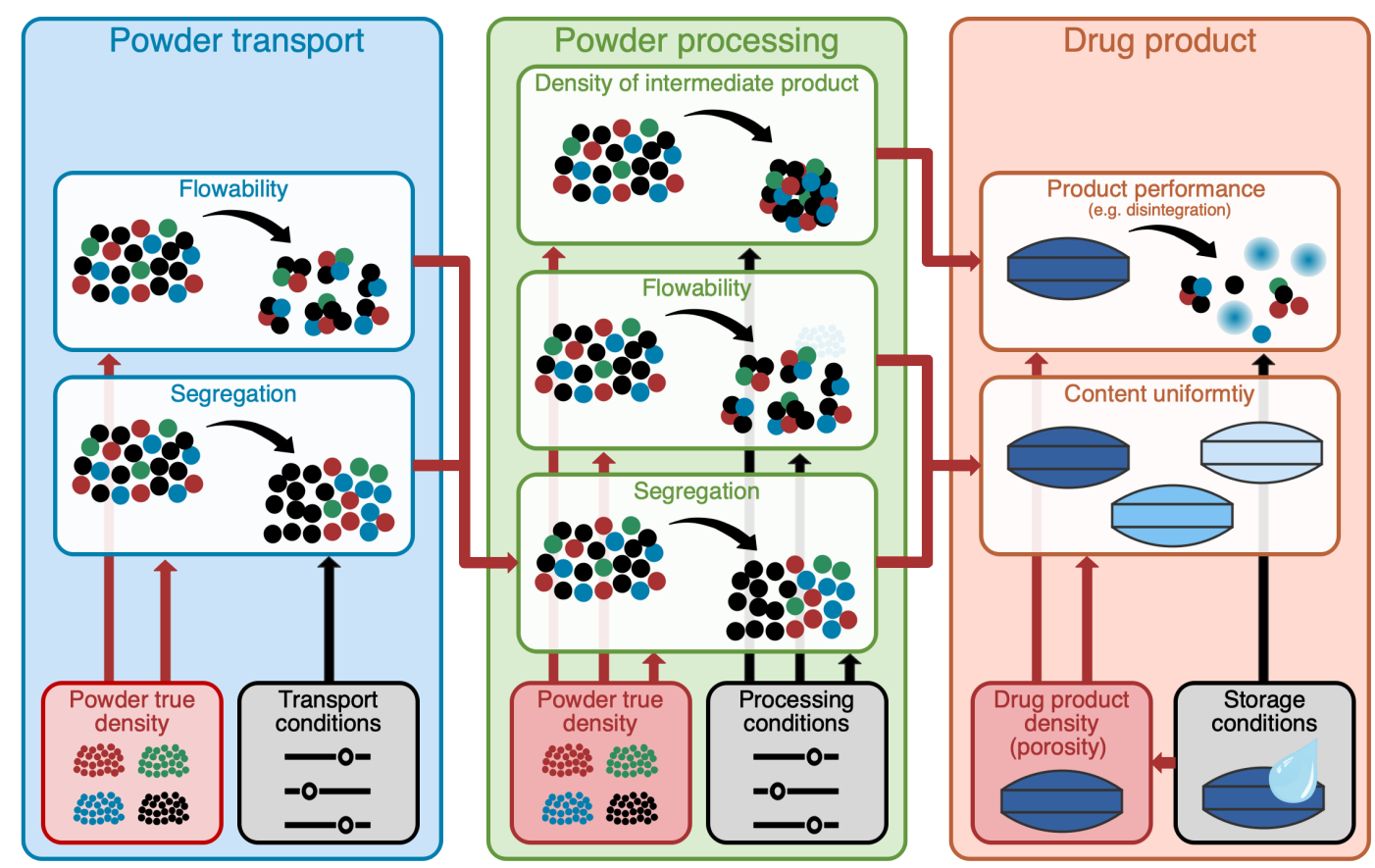

Figure 1: Schematic diagram summarizing the effect of powder and drug product density on critical quality attributes and manufacturability characteristics. The red arrows indicate how powder density affects the transport and processing of powder and also impacts critical quality attributes from the drug product. Also other impacting factors (i.e. the conditions during powder transport, processing and storage of the drug product) are shown, with black arrows.

The following list provides examples where powder density variations are related to CQAs of the intermediate/final product in key unit operations of tableting and capsule filling:

- Powder feeding: In continuous feeding, consistent feeding of the correct mass of individual materials or blends over a long time is required in order to obtain the desired product quality. Powder densification can cause failure modes, such as flow stagnation, feed rate variations associated with hopper agitation and during refill cycles, screw clogging and agglomeration of the fed material as discussed by Hsiao et al. [9]. Consistent feeding of the correct mass of individual materials or blends over a long time is required to achieve high quality of intermediate products, such as granules or extrudates. The crucial condition affecting feeding performance is the local state of material densification at key zones within a feeder, i.e., at the screw inlet region, in the screw and at the outlet [9].

- Granulation: Both granule size and density impact the disintegration of a tablet [6] and hence, have an effect on the dissolution performance of a drug product. The effect on dissolution, however, also varies depending on the formulation, the API and the process settings [10]. The effect of granule density produced via high-shear wet granulation on 
tableting and product performance was demonstrated for example by van den Ban and Goodwin [10]. A change of the granules' properties caused an increase in tablet solid fraction (relative density) and impacted the disintegration and dissolution performance. In terms of manufacturability assessment, it was also shown that an increase in granule filling density impacted the tabletability/compactabiliy and limited the ability to achieve tablets with proper mechanical strength.

- Powder compression: Density variations of the powder blend used for the compaction of a tablet may impact tablet mass and hardness, as well as dissolution performance. Specifically, variations in raw material properties (e.g., particle size, true density), feeder hopper level, amount of lubrication, milling and blending action, applied shear forces in different processing stages can affect powder blend density [11]. In terms of the final product, the relative density (and thus the porosity) are crucial tablet properties that impact mechanical attributes (tensile strength) and dissolution kinetics [12]. Both density changes of granules and tablet thus have an impact on tablet performance [13].

- Capsule filling: Capsule fill weight is considered to be directly related to drug content. Two main filling principles are available, i.e., direct and indirect filling. In the direct filling principle, the machines use the capsule body to directly measure the dose, which is filled as a loose mass. Indirect filling can be done with a dosator nozzle system, a tamp filler, a vacuum drum filler or a vacuum dosator. Indirect capsule filling processes are typically volumetric, i.e., a specific volume of powder or pellets is filled into capsules [14]. As such, only if the bulk powder density remains constant throughout the process the same mass is filled in every capsule, whereas the powder mass is considered to be directly linked to the drug content of the dosage form. A constant powder mass having a uniform blend is required, and consequently, the fill weight variability and the content uniformity are CQAs [15]. The mean capsule fill weight and blend homogeneity are influenced by particle and formulation properties, as well as types of processes and devices [16,17]. Faulhammer et al. [18] developed a design space for low fill weight capsule filling for inhalation products. Operating ranges for two distinctive powder groups (coarse and cohesive powders) which yield products of desired and acceptable quality (fill weight and variability) were suggested and found to show major differences.

- Powder dosing: The quality (fill weight and variability) of capsules filled with powder using the dosator nozzle system is greatly influenced by the powder properties and the process settings used during dosing powder from a powder bed [19]. A simulation study by Loidolt et al. [20] qualitatively showed the influence of powder properties on the amount of 
dosed powder during a dosator process using the Discrete Element Method (DEM). Stranzinger et al. [21] related the measured relative density at sampling positions (i.e. where the dosator collects the powder from the powder bed) to the fill weight of collected capsules filled with powder. The measured powder density (via Terahertz technology) at the powder dosing position was found to be a good indicator for predicting the capsule fill weight.

\section{Powder density definitions and relationships}

This section provides an overview of the definitions of the true (absolute) and relative densities [1].

\section{True density $=$ absolute density $=$ mass $/$ true solid volume}

The true density or absolute densities of finely divided solids is typically measured by pycnometry. Here, a displacement fluid (such as helium, air, mercury, or oil) is used which penetrates the pores of and voids between neighboring particles, thereby providing an estimate of the volume of the solid part of a sample. Detailed descriptions of such measurements are described in Chapter 699 "Density of solids" in the current United States Pharmacopeia (USP) [22].

Apparent density = mass / total volume (envelope volume, i.e., interstitial voids plus true solid volume)

The apparent density measures the density of an ensemble of particles and is therefore a function of the (i) true density, (ii) the internal pore volume or pore space and (iii) the interstitial space between particles. Due to the latter contribution, packing (and thus the processing) of the powder has an impact, i.e., the apparent density is history dependent and lies typically between bulk (also often referred to as poured) and tapped density. In pharmaceutical sciences, the bulk (poured) and tapped density of powdered excipients, drugs, blends, and granulations are commonly determined using the methods described by the American Society for Testing and Materials (ASTM) [23,24], the USP 616 "Bulk density and tapped density" [25], and the European Pharmacopoeia (Ph. Eur.) chapter 2.9.34. "Bulk density and tapped density of powders" [26]. The poured density is obtained when a powder is poured in a container. The second (and higher) one is obtained if the container is tapped via a standard protocol. Note that neither poured nor tapped density are fixed properties, since the type of container and the way of pouring material into the container impacts the values within a small range. In addition, note that in-process material can have any density between poured and tapped density, and can 
even have a lower (when in movement) or higher (when compacted) density.

\section{Relative density $=$ solid fraction $=$ apparent $/$ true density $=1-$ porosity}

The relative density is given as a ratio of densities (density of a mass of the powder per unit volume, i.e., the apparent density, to the true density of the powder), thus is a dimensionless quantity. The relative density is interlinked with the microstructure of a bulk powder through the porosity ( 1 - relative density).

From the descriptions given above, it becomes clear that the true (absolute), bulk (poured) and tapped densities are determined through well-defined standard methods and are characteristics of a powder itself. In contrast, the determination of the apparent density (and the interlinked relative density through true density of the powder), which is highly affected by material processing in a unit operation, is still a challenging task due to absence of well-defined measurement methods and is thus the focus of this article.

Figure 2 schematically illustrates the variation of apparent/relative density in a powder bed. It also highlights the importance of the volume probed by the sensor to resolve density variations in a powder bed. The sample size of a measurement should be representative of a unit dose in order to resolve density variations that can affect the quality of a drug product. More details about sampling and its importance can be found in the ASTM [27].

An important contribution to the relevance of the used sampling strategy was done by Pierre Gy [28]. The theory of sampling (TOS) aims to addresses two fundamental issues: 1) the procedure of selecting a sample, and 2) the amount of material drawn from the process. The book by Esbensen [29] further developed the TOS concept by a unique conceptual framework with which the principles of TOS can be understood in a unifying manner. These references discuss sampling from stationary lots as well as from moving, dynamic processes (process sampling), while the latter is especially relevant in the context of this review. 


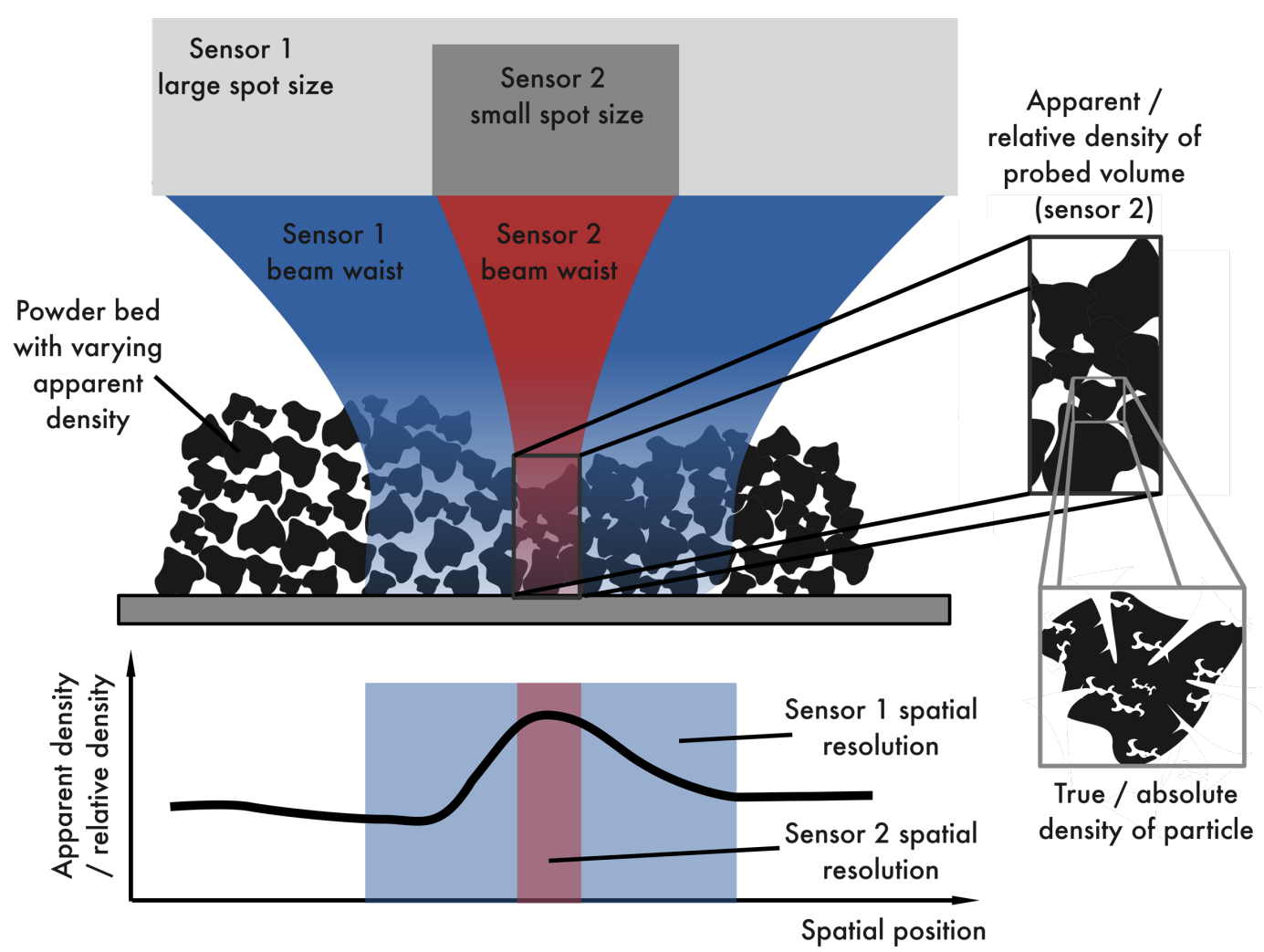

Figure 2: Schematic diagram illustrating the apparent density variations in a powder bed and the importance of measurement resolution.

\section{Monitoring powder density variations in the framework of FDA's PAT initiative}

Pharmaceutical developments and manufacturing practices often rely on a number of off-line tests to assess, whether a final product meets the quality requirements. To overcome this, a series of guidelines regarding PAT and QbD have been released by the FDA [30] and ICH (Q8Q11) [31] encouraging the development of methods with the goal to build quality assurance into the manufacturing process. A key requirement of the initiative is the ability to verify product quality already during manufacturing by measuring critical quality attributes using appropriate process monitoring tools [32]. Access to powder density variations during manufacturing could provide important information in synergy with the PAT initiative [30] to enhance end product quality [11] and enable real-time release of the product [12]. Furthermore, as the pharmaceutical industry moves from batch towards continuous processing [33-35] with solid oral dosage forms as one of the primary candidates [35], real-time quality monitoring of in-process material is an essential building block [36].

Based on the FDA's PAT initiative [30], the following real-time measurement modes can be 
performed to monitor variables of a process:

(1) At-line, where the sample is removed and analyzed in close proximity to the process stream.

(2) On-line, where the sample is diverted from the manufacturing process, and may be returned to the process stream.

(3) In-line, where the sample is not removed from the process stream and can be invasive or non-invasive.

The revised and elaborated Ph. Eur. chapter 5.25 "PAT - Process analytical technology" [37], which aims to support the application of PAT, addresses aspects regarding the interfacing mode (e.g. 'off-line', 'at-line', 'on-line' and 'in-line') of analytical techniques with the manufacturing process.

Much of the current literature in the manufacturing of solid dosage forms pays particular attention to techniques for in-line monitoring of the blend uniformity as discussed in Wu and Khan [38]. Even if blend uniformity is adequate, density variations of the powder and the product may lead to undesirable changes in the product performance. Density variations can either cause an excess/lack of drug in a single dose or it can impact the microstructure which also influences the dissolution behavior of the final product [13]. It is thus crucial to control not only the drug concentration but also the relative density during processing. However, monitoring the variation in the relative density throughout the process without any disturbance (i.e., the in-line mode) is still a challenging task due to the following reasons:

(1) Large variation in material properties, such as particle size and shape and also true density (especially for blends).

(2) Sampling a representative volume at high speed.

(3) Decoupling of density variations from concentration variations in blends.

(4) Most importantly, there exists no sensing principle that can measure density directly via contactless methods.

\section{Technologies for monitoring of powder density variations}

A comprehensive analysis of all available techniques is beyond the scope of this article and the reader is referred to review articles for pharmaceutical tablets [39] and for geological samples [40]. This review article focuses on the primary technologies with potential for continuous monitoring of powder density variations in a non-invasive manner. Some of the technologies presented in this review article have already been used for in-line monitoring of powder density 
in a pharmaceutical context. This section also discusses some techniques which are currently used as at-line/on-line methods or in areas beyond pharmaceutical manufacturing but have the potential to become an in-line technique for monitoring density variations of pharmaceutical powders.

The technologies discussed in this review article utilize the interaction of electromagnetic radiation and matter (near-infrared spectroscopy (NIRS) and NIR chemical imaging (NIR-CI), Terahertz (THz) spectroscopy and imaging, X-ray based methods, microwave), sound waves (ultrasonic, acoustic emission (AE)) and electrical current (electrical tomography) to probe the sample. Figure 3 shows a general trend in the use of these key technologies in the pharmaceutical industry for monitoring powder density variations (either at-line, on-line or inline) in various unit operations.

NIRS (including NIR-CI) is clearly the dominant PAT used in pharmaceutical applications for monitoring powder density variations. Real-time monitoring of powder density using NIRS has been reported (this is described in the following section). In recent years, another promising technology, namely terahertz technology, has gained popularity in the pharmaceutical industry. Ultrasonic technology is another technology that is widely applied in the field of pharmaceutical research. Its use for real-time monitoring of mechanical properties of a compact (tablet) during compression along with the link to the product quality performance has been reported, making it a valuable tool for the pharmaceutical manufacturing industries and regulatory agencies. Besides those three in-line technologies, X-ray techniques have gained increasing interest in the past decade, however so far mainly for off-line and some at-line applications. 


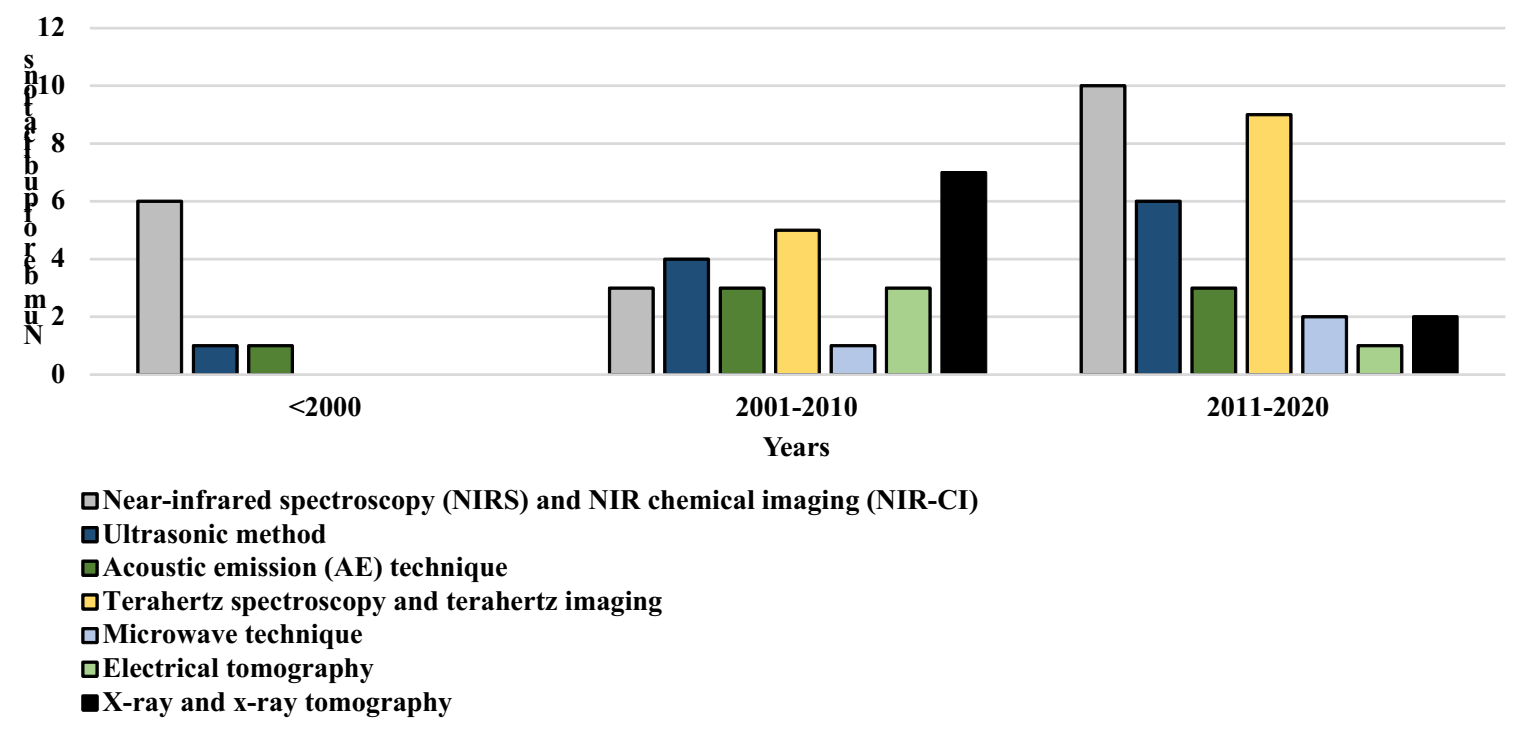

Figure 3: Trend in the use of the key technologies in the pharmaceutical industry (only articles mentioned in section 4 are accounted for).

In the following sections, the basic principles and instrumentation are described for each technology and application examples are provided, whereas the main focus was on case studies with the most relevant/similar applications suitable and adaptable for static and moving powder streams in pharmaceutical unit operations. Note that in the following sections "relative/apparent density" is referred to as "powder density".

\subsection{Near-infrared spectroscopy and chemical imaging}

\subsubsection{Basic concept and instrumentation}

Near-infrared spectroscopy (NIRS) is one of the most commonly used analytical tools in the pharmaceutical industry. The ASTM defines the NIR region of the electromagnetic spectrum as the wavelength range of 780-2526 nm corresponding to the wave number range of 12820-3959 $\mathrm{cm}^{-1}$. The most prominent absorption bands occurring in the NIR region are related to overtones and combinations of fundamental vibrations of $-\mathrm{CH},-\mathrm{NH},-\mathrm{OH}$ (and $-\mathrm{SH}$ ) functional groups [41]. Basic principles of NIRS (amongst other vibrational spectroscopic techniques) can be found in Siesler et al. [42].

A NIR spectrometer is generally composed of a light source, a monochromator, a sample holder or a sample presentation interface and a detector, allowing for transmittance or reflectance measurements. The appropriate NIRS measuring mode is prescribed by the optical properties 
of the samples. Transparent or semi-transparent materials in the NIR region are usually measured in transmittance. Turbid liquids or semi-solids and solids may be measured in diffuse transmittance, diffuse reflectance or transflectance (i.e., a combination of transmissive and reflective sampling), depending on their absorption and scattering characteristics [43]. Diffuse reflectance is preferred and the most frequently applied mode for in-process measurements of solid dosage forms [44].

NIR imaging is a combination of NIRS with digital image processing. An NIR imaging system is basically composed of an illumination source, an imaging optic, a spectral encoder selecting the wavelengths, and a focal plane array (FPA). NIRS and imaging are fast and non-destructive analytical techniques that provide the chemical and physical information of virtually any matrix [43]. Hyperspectral imaging is a further development which combines the advantages of machine vision and spectroscopy. Here, spectroscopy exhibits chemical information, composition and pollution of materials; machine vision gives information about spatial distribution, texture, and shape, as discussed in the work of [45].

Spatially resolved spectroscopy (SRS) has a position in between single-point spectroscopy (NIRS) and hyperspectral imaging. This technique was initially introduced for the determination of optical parameters (i.e., absorption and scattering coefficients). The method provides spatial information while simplifying quantitative modeling capabilities. One or several light sources and several collection channels are used. The collection channels are located with respect to the sample illumination source(s). Spectra collected by the channels located in close proximity to the light source exhibit strong scattering phenomena, whereas absorption is stronger as light travels deeper into the sample. Numerous spectra are collected in the course of one single measurement, with the same probe representing different degrees of light absorption and scattering [46].

In combination with multivariate data analysis NIRS and imaging open many interesting perspectives for both qualitative and quantitative analysis [43]. Chemometrics (multivariate calibration models) is used for systematic data processing of NIR spectra and extraction of physical and chemical properties. This requires the careful development of robust multivariate calibration models and validation of the developed models to reliably use NIRS for this purpose [47]. Developing a NIR calibration model for monitoring powder bulk density changes requires spectra collected for powder samples of various densities. The powder bulk density is related 
with the baseline shift of the NIR spectra [11].

\subsubsection{Application examples}

Recently, a detailed description of NIRS and its applications has been reported by Ozaki et al. [48]. NIRS is currently the fastest-growing and the most versatile analytical method not only in the pharmaceutical sciences but also in the industry [49]. Over the past few decades, NIRS has found a vast number of applications in the analysis of physical-chemical and functional properties of pharmaceutical tablets [47]. De Beer et al. [50] provided a good review of the use of NIRS as PAT, i.e. during processing, with special emphasis in pharmaceutics and dosage forms. Another thorough review by Jamrógiewicz [49] covers the applications of NIRS in a pharmaceutical setting.

This section focuses on application examples of NIR for the real-time monitoring of powder density. Ellison et al. [51] showed the effectiveness of NIR-CI in the qualitative and quantitative determination of intra-tablet density variation as a function of lubricant (magnesium stearate) concentration and the resulting changes in the die wall friction during compaction of tablets. Souihi et al. [52] demonstrated the use of NIR-CI in combination with multivariate methods to spatially map physical properties and content of roller compacted ribbons and tablets. Ribbon density could be determined in a non-destructive manner and density distributions could be studied across the width and along the length of the ribbons. Khorasani et al. [53] reported the use of NIR-CI in combination with multivariate data analysis to visualize and predict the porosity (relative density) distribution of ribbons. Another study by Khorasani et al. [54] demonstrated that at-line NIR-CI combined with a chemometric data analysis can be utilized as a non-destructive tool with real-time potential to monitor and visualize the porosity distribution in ribbons. This information together with the granule size after milling of the ribbons, could be used to predict the downstream processing performance (i.e., the tablet tensile strength). Another study by Singh et al. [11] demonstrated the real-time monitoring of powder bulk density variability and its use in a control system for powder feeding operations. Figure 4 shows their experimental setup and the real-time measured powder bulk density at the feeder outlet. A chute has been directly connected with the feeder outlet and the NIR sensor has been integrated with the chute. This integration of an NIR sensor in the feeder setup facilitated the real-time monitoring of powder bulk density changes. Feeder scew rotational speed has been considered as a means for qualitative verification of measured powder bulk density. A feedforward controller for powder bulk density has been proposed based on the finding of the study. 
In a more recent study by Román-Ospino et al. [55], the importance of developing proper NIRS calibration models for real-time prediction of powder density during continuous manufacturing (CM) was emphasized. Three techniques to introduce the required variation in powder density for calibration sets were tested and compared to the NIR spectra obtained in real time in a CM plant. It was found that calibration techniques, using different strain levels in powder blends (and as a conseuqence different powder densities) showed the greatest similarity with blends produced in the CM plant. The work of Ortega-Zúñiga et al. [56] demonstrated the development of NIRS calibration models for powder density predictions within a feed frame. The findings highlight the potential of NIRS measurements within the feed frame for a PAT method to control the critical properties, such as tablet mass, hardness and dissolution in batch and CM processes. 

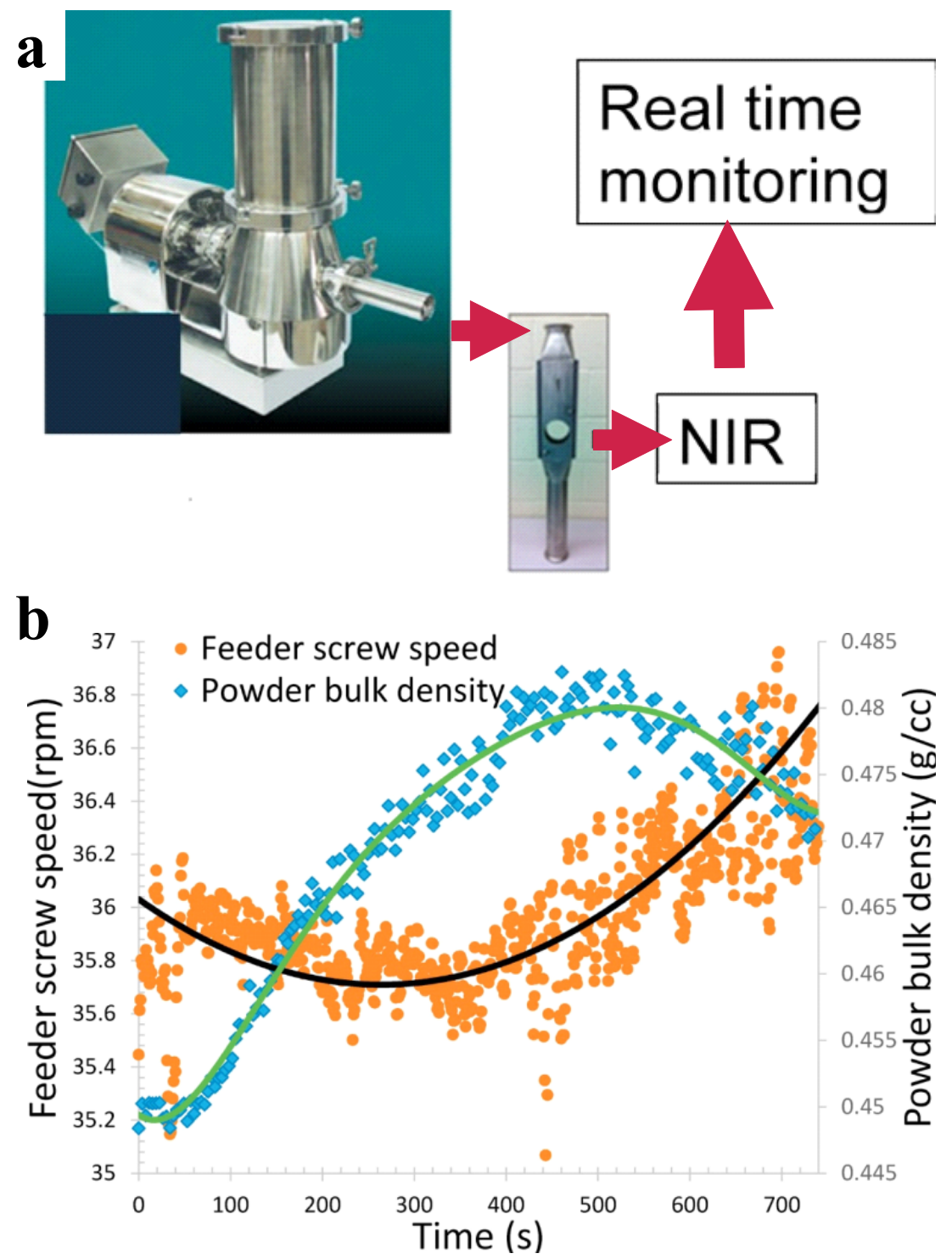

Figure 4: Real-time monitoring of powder bulk density using NIRS. (a) Integration of an NIR sensor in a feeder for real-time monitoring of powder bulk density, where a cylindrical chute is used to interface with the NIR sensor. (b) Real-time measurement of powder bulk density at the feeder outlet and qualitative validation via feeder rotational screw speed (rpm) (Reprinted with modifications from [11] with permission from Elsevier).

\subsection{Ultrasonic method}

\subsubsection{Basic concept and instrumentation}

Ultrasonic techniques generate and measure a low amplitude sound wave that propagates through a sample. The stimulus can be, for example, a mechanical impact or powerful light impulse, where the latter is referred to as a photoacoustic technique. Ultrasonic instruments are designed to generate ultrasonic waves of a defined frequency range. Measurements can be performed either in a pulsed echo or a through-transmission mode. In a pulsed echo mode, 
sending and receiving of ultrasonic waves is done with the same transducer, whereas in the through-transmission mode the ultrasonic signal is transmitted through a sample and received by another transducer $[57,58]$. Analytical ultrasonics refer to the utilization of low-power ultrasonic in high frequencies as a non-destructive measuring technique [59]. The interaction of sound waves with matter alters both the velocity and attenuation of the waves due to absorption and/or scattering mechanisms [60].

An important fact for the applicability of the ultrasonic technique to monitor density variations of a tested material is that the transmission of the wave (and speed) is dependent on the medium properties, e.g., density and elasticity. In isotropic solids, the shear rigidity of the medium couples the longitudinal and transverse wave components together. The speed of sound here thus depends on both the bulk and shear modulus of the medium itself [61].

For using ultrasonic techniques for in-line monitoring of powder properties, the method must be non-destructive and contactless. This can be realized in ultrasonics applying either an aircoupled ultrasonic technique or a laser ultrasonic technique. In air-coupled ultrasonics, the coupling medium is air or another gas which is part of the natural environment and therefore no additional contact is required. The use of air coupling is particularly attractive, because it results in ultrasonic probing signals whose temporal and spatial characteristics are similar to those generated using water coupling [62]. Grandia and Fortunko [62] highlight the differences between liquid-coupled and air-coupled ultrasonics. Laser ultrasonics is a method to generate and detect ultrasonic signals remotely with the aid of lasers without requiring direct physical contact between probe and sample. A good overview about the principles of generation and detection, advantages and disadvantages of the method, as well as industrial applications is provided by Monchalin [63]. Fundamental physics of the ultrasonic technique (e.g., the propagation of ultrasonic waves in different media) can be found in Shutliov et al. [64].

\subsubsection{Application examples}

The ultrasonic technique is widely used for non-destructive testing in many different areas. Awad et al. [65] provide a broad overview of ultrasonic applications in analysis, processing and quality of food. Ultrasonic parameters like ultrasonic velocity, attenuation coefficient and acoustic impedance are used to characterize physicochemical and structural properties of foods. A recent review by Mohammadi et al. [59] emphasizes the use of analytical ultrasonic in the field of contactless and non-destructive monitoring of dairy products with particular benefits in 
its cost-effective implementation, fast measurements, and accurate evaluation.

With respect to the application of analytical ultrasonics for monitoring density of granulate matter, general studies on the characterization of physicochemical and composition properties (e.g., relative density) of various materials (such as metals [66], cereal products [67] to name only a few) provide useful information about the applicability of the method for this purpose.

The ultrasonic method is also widely applied in the field of pharmaceutical research. Since ultrasonics use a mechanical wave, the speed of sound is sensitive to mechanical properties, and thus, it has been used to determine the porosity and elastic modulus of tablets and coating thickness [58,68-76]. As an example, Figure 5 shows the wireless transmission of ultrasonic waveforms for monitoring drug tablet properties and defects as reported by Stephens et al. [70]. A tablet compaction apparatus utilized to house the instrumented and customized type B tooling was used in the study. The reflection of an ultrasonic pulse generated by a transducer, embedded in the upper punch, propagating through the upper punch-tablet interface and reflected from the lower punch-tablet interface can be acquired during compaction. The authors discussed, how the ultrasonic technique enables the characterization of mechanical properties and integrity of tablets during compaction. The characterization of geometric and mechanical properties of tablets, as well as integrity in real-time is of interest to the pharmaceutical manufacturing industry and to regulatory agencies, since those monitored parameters are directly related to tablet hardness (affecting bonding, mechanical strength, and relating to the Young's modulus) and porosity for its effect on dissolution profiles. 

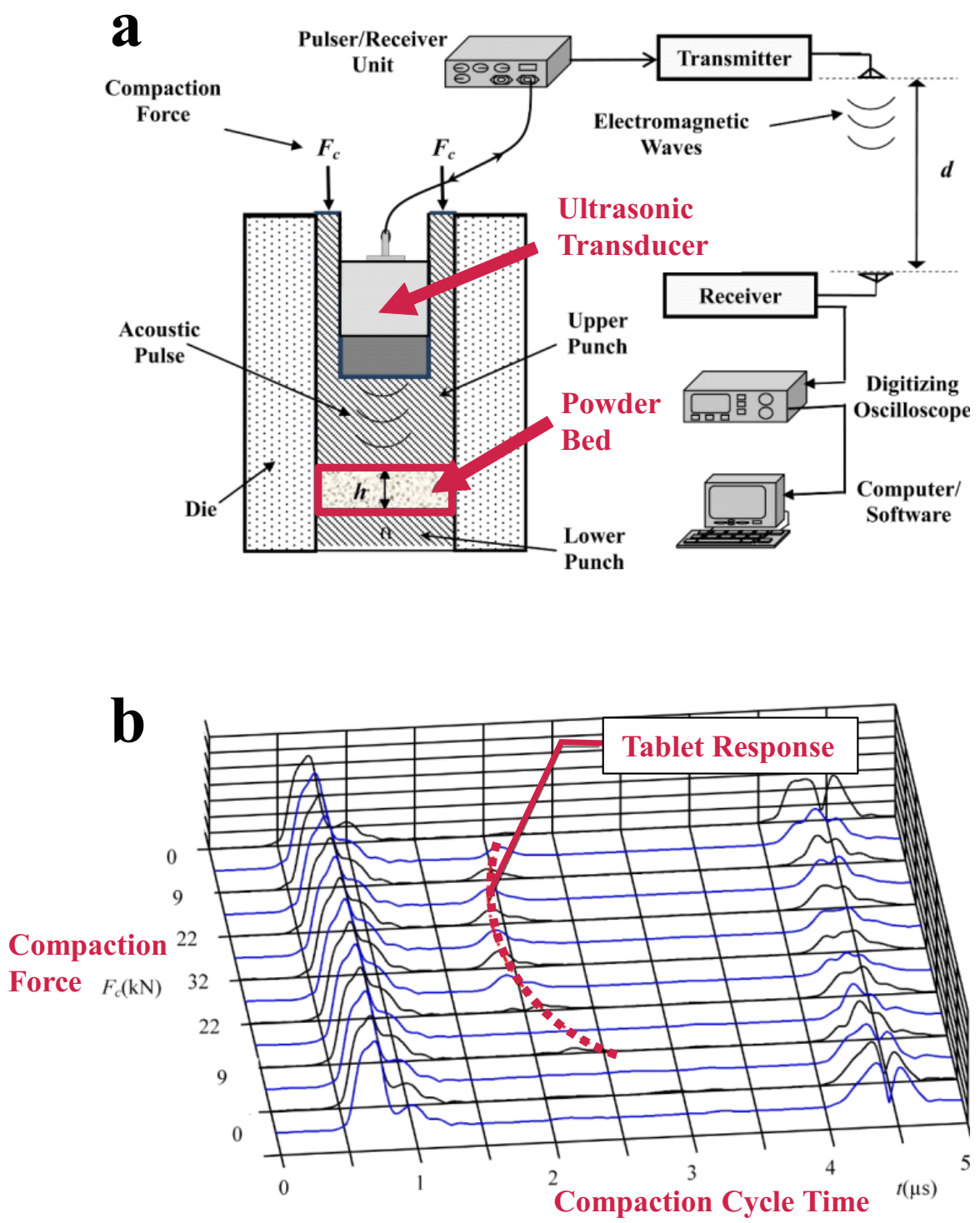

Figure 5: Ultrasonic method for in-die compaction monitoring: (a) Instrumentation diagram of the experimental setup and (b) waterfall representation of 14 signals processed waveforms at consecutive compaction force levels $\left(F_{c}\right)$ in a full compaction cycle with the change in decreasing time-of-flight (Reprinted with modifications from [70] with permission from Elsevier).

\subsection{Acoustic emission (AE) technique}

\subsubsection{Basic concept and instrumentation}

The acoustic emission (AE) technique is based on the detection and analysis of sound produced by a process or a system [77]. AE is a passive method of monitoring transient elastic stress waves, generated by the rapid release of energy when a material undergoes a change at the atomic scale, such as plastic deformation or cracking. These generated surface waves produce a voltage output which is detected by piezoelectric sensors attached to the surface of the 
structure. All signals with an amplitude greater than a user defined threshold are recorded and subsequently stored on a AE acquisition system [78]. A detailed explanation of AE can be found in Grosse and Ohtsu [79], and in Scruby [80].

The most common method for detecting acoustic emissions is via the attachment of a transducer to the outside of a vessel or pipe for non-invasive measurements [81]. When attaching an AE sensor to a measurement surface, a couplant material is used to remove any air from the interface. The reason for doing this is that the acoustic impedance of air is much lower than that of the sensor face or material surface and would therefore cause a considerable loss in transmission. The sensor response is influenced by various couplant materials. It was reported that a high-performance ultrasonic couplant can significantly improve the sensor sensitivity compared to a grease-type couplant [82].

The AE technique is highly sensitive and the measured signals may contain a great number of transients from sources located both in the object and the environment. The work by Unnpórsson [83] provides an expample AE signal from a dry powder flowing along a fluidized bed stainless steel chamber wall. High transients could be detected from this AE signal. The object sources include surface vibration, collisions and friction between particles or particles and surface and changes in the material matrix, e.g., due to heating. Furthermore, certain AE waves can be masked by the AE generated from friction and rubbing. The AE method depends greatly on the physical properties of materials (e.g., particle size) and it is highly sensitive to particle density and/or size variations [81].

\subsubsection{Application examples}

In recent decades, AE has been widely used as a non-destructive testing method. Examples are inspection of aircraft wings, pressure vessels, loading-bearing structures, mechanical integrity of bridges and components just to name a few [84]. The use of the AE technique for a wide range of particulate processes such as powder mixing, crystallization, high-shear granulation, drying, various fluidized bed process, heterogeneous reactions has also been reported in the literature.

The AE concept was demonstrated for continuous bulk density measurements [85], and used as an acoustic sensor for measuring particle size in flowing bulk solids [86]. Later, Davies et al. [87] reported the potential of an acoustic sensor for in-line bulk density measurements and mean size measurements in process applications. Crouter and Briens [88] demonstrated the feasibility 
of $\mathrm{AE}$ in investigating, detecting and in-line monitoring of changes in the particle flowability upon addition of lubricants using a V-blender. Furthermore, the review by Dave et al. [89] describes AE as a potential analytical tool for non-invasive characterizing physical-mechanical properties of tablets, which might be a valuable basis for establishing this method for monitoring the bulk density variations. Recently, Ruiz-Carcel et al. [90] reported the use of acoustic emissions for estimating the powder mass flow rate in a screw feeder (Figure 6). The examples of acquired AE signals in Figure $6 \mathrm{~b}$ show how the signal peak amplitude is higher for powders with higher density. The authors reported that with this approach it will be possible to measure powder flow rate in-line and in real-time.

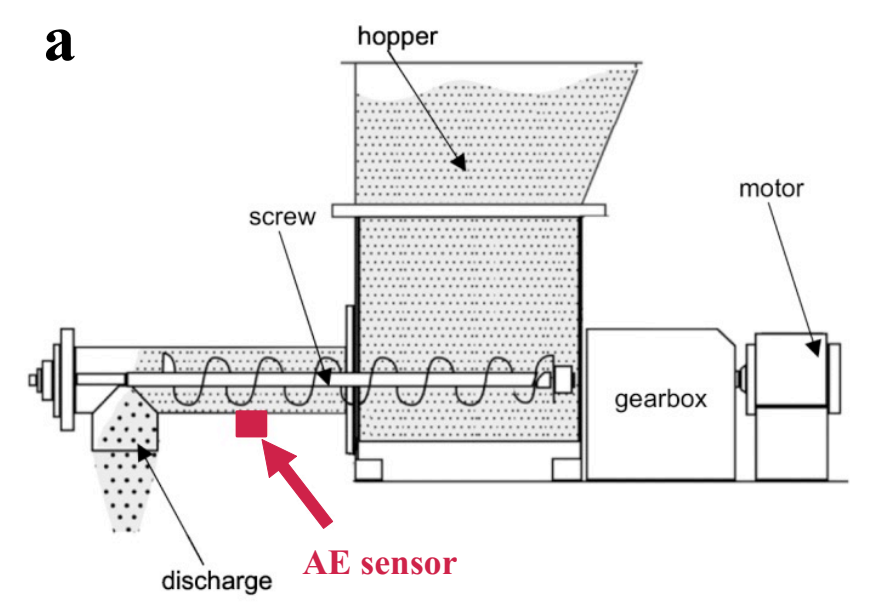

b

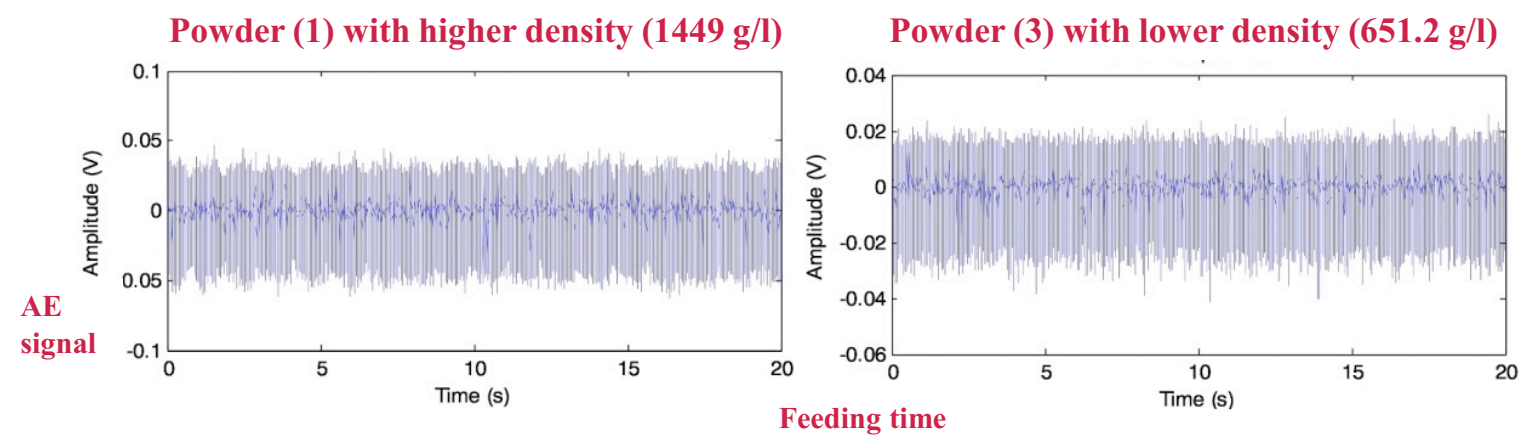

Figure 6: Acoustic emissions for the estimation of the powder mass flow rate in a screw feeder: (a) Diagram of the experimental setup and (b) examples of acquired AE signals for a powder with higher density (1449 g/l) (left) and a powder with lower density $(651.2 \mathrm{~g} / \mathrm{l})$ (right) at $50 \mathrm{~Hz}$ powder mass flow rate in the feeder (Reprinted with modifications from [90] with permission from Elsevier). 


\subsection{Terahertz spectroscopy and terahertz imaging}

\subsubsection{Basic concept and instrumentation}

Terahertz electromagnetic radiation covers the spectral range from $2-130 \mathrm{~cm}^{-1}(60 \mathrm{GHz}-4 \mathrm{THz})$ [91] and this spans the range between mid-infrared and microwave radiation. In contrast to the mid-infrared region, which is related to intra-molecular vibrations, the terahertz region is dominated by inter-molecular vibrations, corresponding to coherent, delocalized movements of large number of atoms and molecules [44]. Since the radiation lies between the electronics and optics regions, terahertz techniques combine advantageous properties of both regions: It can penetrate most dielectric materials in the same way as microwaves, and it features spectral absorption of most polar molecules, such as in infrared region, which is beneficial for chemical identification and sensing applications [92]. Compared to NIR, mid-IR, and Raman spectroscopy, terahertz time-domain spectroscopy is inherently less vulnerable to scattering effects from powders due to operating at much longer wavelengths [93] and excipients most commonly used for the formulation of solid dosage forms are transparent, or semi-transparent, to terahertz radiation. Hence, the pulse of terahertz light can penetrate into and through a specimen leading to a large representative sample volume. The penetration depth of the terahertz radiation into the sample material is dependent on the material and the power of the terahertz pulse. At present, penetration depths into typical pharmaceutical tablets have been demonstrated up to $5.3 \mathrm{~mm}$ [13]. Detailed description of the theory of terahertz spectroscopy and instrumentation can be found in numerous earlier studies and reviews [94-98]. Physics and application of terahertz radiation are described in detail by Roux et al. [99], including characteristics and performances of a classical set-up, and explanations of the extraction of the refractive index and absorption coefficient from transmission or reflection measurements.

\subsubsection{Application examples}

Detailed reviews on pharmaceutical applications of terahertz pulsed spectroscopy and imaging were published by Zeitler et al. [91], Ho et al. [100], Taday [101] and Shen [102]. In addition many reviews on other applications, such as the food and agro-food industry [103-105], imaging of biologically related applications [106], fundamental research and industrial applications [107], have been published. Recently, Prabhu [108] provided a comprehensive overview and summary of recent advances and applications of terahertz spectroscopy and Naftaly et al. [109] reviewed industrial applications with a focus on non-destructive testing of terahertz spectroscopy and imaging. 
Terahertz spectroscopy and imaging provide access to the frequency dependent refractive index, which is directly related to the density of a sample [39,110-112]. The measured refractive index or a sample is a function of the fill fractions of each constituent and the total porosity (1 relative density). It can therefore be used to determine the porosity of a tablet within seconds by knowing the other fill fractions (e.g., knowing the formulation). This relationship was utilized by a range of studies to analyze density distributions of tablets, tablet porosities and ribbon densities. Palermo et al. [113] demonstrated the ability to quantitatively measure density maps of tablets using terahertz pulsed imaging (TPI). Juuti et al. [114] investigated starch acetate tablets using terahertz spectroscopy. The time delay, which depends on the sample refractive index, of the terahertz pulses transmitted through a tablet was found to correlate with the porosity of the tablet across a range of compression pressure. The work by Ervasti et al. [115] showed that in the absence of terahertz scattering, the effective refractive index that is obtained by the detection of the terahertz pulse delay correlates with the porosity of the tablet. Additionally, it was proposed that the broadening of the terahertz pulse could be a measure of porosity of tablets that scatter terahertz radiation. Bawuah et al. [111] investigated the dependence of porosity on other physical quantities, such as gloss and surface roughness and introduced a method for the non-destructive and the non-invasive estimation of the porosity of tablets using effective medium theory. More details about the terahertz-based porosity measurement can be found in Markl et al. [39] and Bawuah et al. [112].

Recently, Stranzinger et al. [116] demonstrated that powder density variations in a rotating container (mimicking a capsule filling apparatus) can be captured and analyzed by means of terahertz pulsed imaging (Figure 7). This setup and methodology were capable of spatially resolving relative density variations as small as $0.3 \%$ (Lactohale 100) in a moving container. Different pharmaceutical powders were studied in a rotary container, compacted to various relative densities and related to in-line terahertz measurements acquired during operation. Compacting the powder bed (decreasing the powder bed height and increasing the relative density) resulted in an increase in the refractive index of the powder. This relationship was used to develop a linear model which is capable of predicting the relative densities of the powder in the container. In a further study [21], we applied this new terahertz-based density measurement method to analyze the correlation of the measured powder bed density with the fill weight in a capsule. This was performed by drawing small quantities from the powder bed using a novel sampling system that mimics the capsule filling process in proximity to the rotating container. Hence, the relative density of the powder bed was monitored and correlated with off-line weight 
measurements to predict the fill weight based on the terahertz reflection measurement.
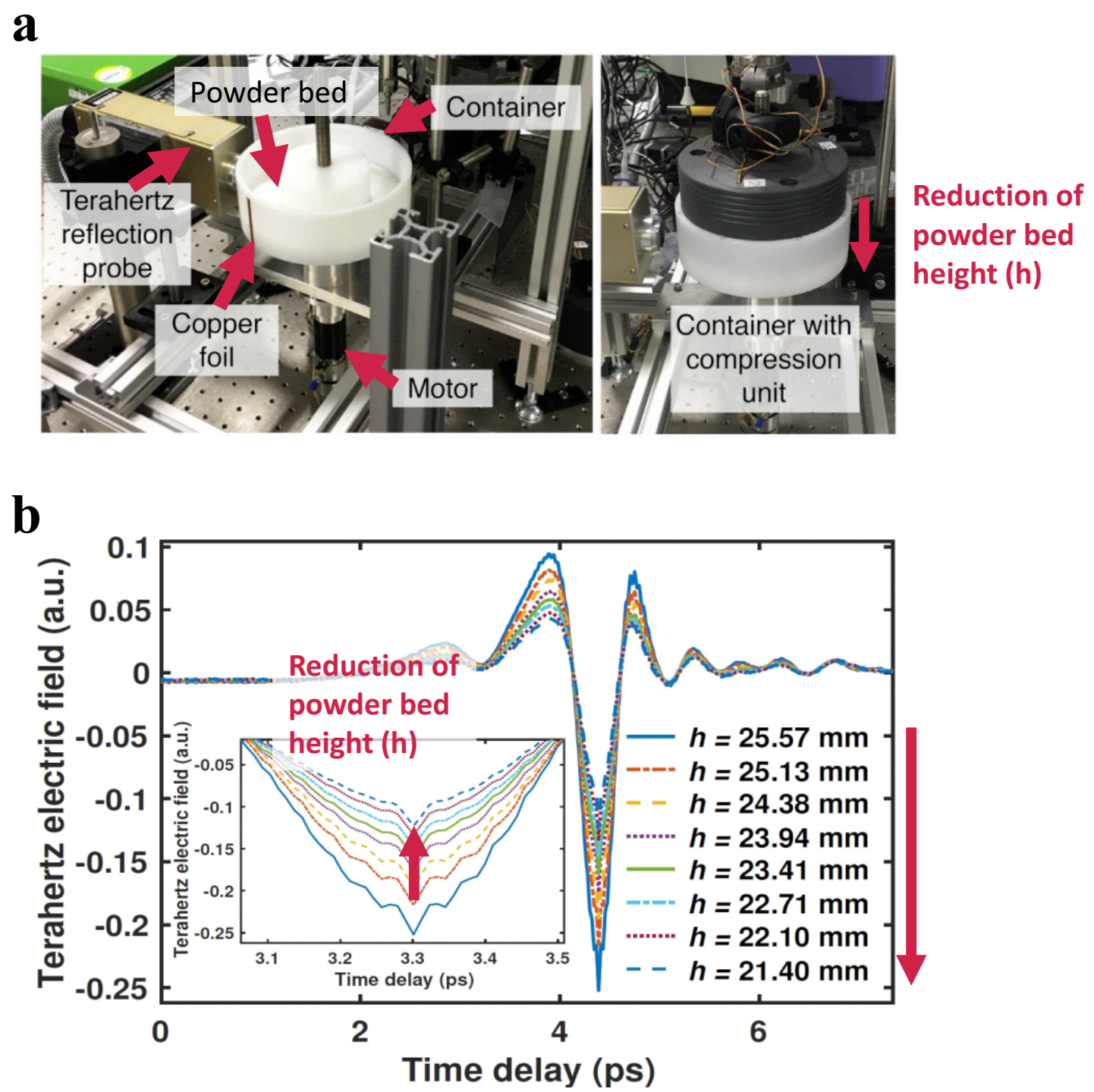

Figure 7: Aligned and averaged terahertz time-domain waveforms for various displacements of the experiment with Lactose 220 at a motor speed of $4 \mathrm{rpm}$ (Reprinted with modifications from [116] with permission from Elsevier).

\subsection{Microwave technique}

\subsubsection{Basic concept and instrumentation}

Microwaves are a form of electromagnetic radiations with waves in the wavelength from $1 \mathrm{~mm}$ to $1 \mathrm{~m}(300 \mathrm{MHz}$ to $300 \mathrm{GHz})$ [117]. Microwaves can easily propagate through low-loss substances, such as plastics, glass, ceramic, etc. [118-123]. The principle of the microwave sensing technique is based on measuring the dielectric properties of a sample and utilising its relationship to chemical and physical properties of the material [120,123,124]. Detected 
changes can be linked to the material type, e.g., composition and concentration of the constituents of the sample [123]. A detailed description of the microwave theory can be found in Adam and Packard [125].

The analysis can be conducted either in transmission or reflection mode. In the transmission mode the amplitude and phase shift of transmitted microwaves are measured (e.g. horn antenna), and in the reflection mode one antenna emits and detects the signals which are reflected from a sample [126].

Furthermore, the microwave sensing technique can also be used as an imaging method, i.e. microwave tomography. The basic principle of microwave tomography is to measure the scattered electromagnetic fields produced by an object and to generate images of dielectric properties. The scattered microwave field is measured around the object from different angles, creating multiple views of the object [127].

It is generally possible to perform non-destructive and on-line testing of material properties, geometric dimensions (e.g. thickness) and detection of defects like flaws, cracks, delaminating or voids by means of microwaves. Often the examination can be performed without contact and preferred materials to be tested are dielectrics since they are partly transparent with respect to microwaves [128].

\subsubsection{Application examples}

The fields of application encompass different domains like determination of bulk density and moisture in particulate materials [129], measurements of the dielectric properties of various materials/substances [130-132], monitoring of glucose concentration [133,134], multiphase flow monitoring [135], characterization of construction materials [121,122], real-time identification of the vegetable oil types [123], to name a few. In Dobmann [128] a selection of microwave applications papers is provided, such as the characterization of coatings, like measurement of coat thickness, detection of defects, inclusions, delaminating and voids in bulky objects, determination of anisotropies in fibre reinforced plastics and surface characterization of metal sheets.

For granular and particulate materials, the dielectric properties are not only dependent on frequency, temperature, and composition of the material but also on changes in the bulk density [136]. For example, the work of Trabelsi et al. [137] reported the determination of bulk density and moisture content of granular and particulate materials from measurements of their dielectric properties at a single microwave frequency. The calibration equations used for bulk density and 
moisture determination were originally developed for cereal grains and oilseeds $[122,138]$. Bulk density was also determined independent of moisture and temperature. Figure 8a-c shows examples of typical setups of microwave systems and results shown in Figure 8d corresponds to the setup shown in Figure 8c.
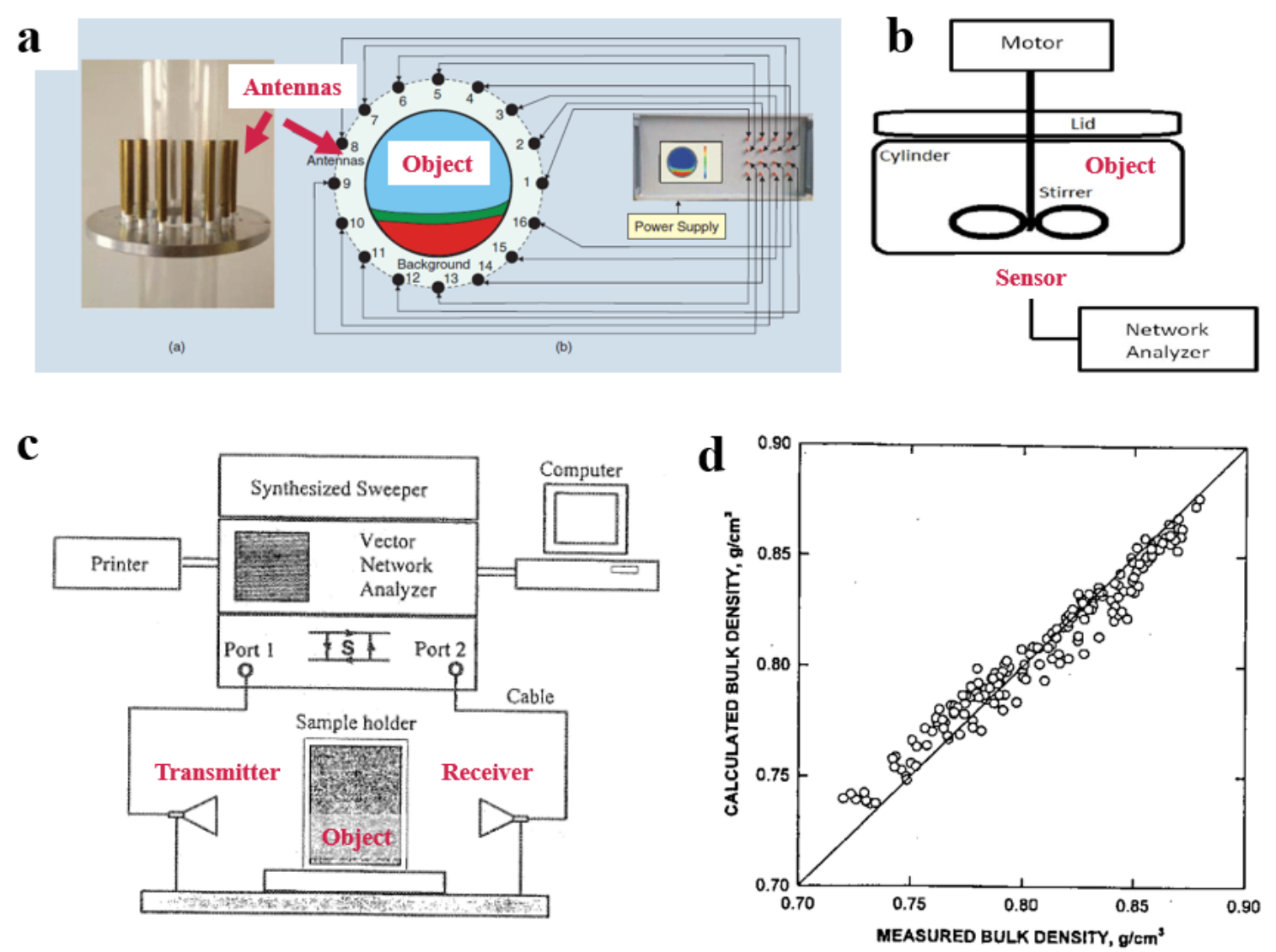

Figure 8: Microwave method for industrial applications. (a) A typical antenna setup and a diagram of a microwave system, (b) schematic of microwave sensor and stirring apparatus, (c) block diagram of the measurement set-up for results shown in (d) predicted bulk density from microwave permittivity measurements at $14.2 \mathrm{GHz}$ as a function of gravimetrically measured bulk density for hard red Winter wheat (Reprinted with modifications from [127,139], and [129] with permission from IEEE, and from [140] with permission from Taylor \& Francis.

[139] [140]

Microwave sensors systems have been used for real-time moisture sensing in many industrial areas for decades, e.g., in the agricultural [141,142], food [143-145] and wood processing industries [146]. In 2008, first in-line applications in pharmaceutical processes were successfully introduced by Buschmüller et al. [147]. The technology did not yet find its way into pharmaceutical applications to the same extent as the near-infrared (NIR) sensor systems [148-150]. However, in contrast to NIR, one benefit of microwave sensors is that microwaves can penetrate orders of magnitude deeper and hence probe a larger sample volume yielding more representative results [151]. For future in-line applications of the microwave sensor in the 
pharmaceutical world, a thoroughly developed and validated method is crucial, especially as microwave sensors must be calibrated separately for different materials [151]. Furthermore, recent advances and new challenges in microwave tomography systems for industrial process monitoring (particularly real-time monitoring systems) are highlighted in the work of $\mathrm{Wu}$ and Wang [127].

\subsection{Electrical tomography}

\subsubsection{Basic concept and instrumentation}

Electrical tomography can be divided into two methodologies: electrical capacitance tomography (ECT) and electrical impedance tomography (EIT). Electrical resistance tomography (ERT) is a particular case of electrical impedance tomography. ECT and EIT produce images based upon variations in permittivity and conductivity, respectively [152]. A detailed description of the theory of ECT can be found in Beck et al. [153], and of ERT in Daily et al. [154].

\section{Electrical capacitance tomography (ECT)}

The permittivity distribution of an object is imaged by measuring the electrical capacitances between sets of electrodes placed around its periphery. Materials with contrast in dielectric permittivity are imaged using exterior measurements capacitance across a system of electrodes to get a permittivity distribution of the object [155]. A typical ECT sensor is comprised of an array of conducting plate electrodes, mounted on the outside of a non-conducting pipe and, surrounded by an electrical screen. For metal walled vessels, the sensor must be mounted internally using the metal wall as an electrical screen [156].

The subsequent reconstruction of the permittivity distribution (which is related to the solid distribution of a gas-solid mixture) based on measured capacitance values requires suitable image reconstruction algorithms. The work by Yang and Peng [157] gives a comprehensive overview of image reconstitution algorithms used in ECT.

The image resolution of ECT is in the $\mathrm{mm}$ range. With an increasing number of electrodes the image resolution can be enhanced; but the larger the electrode number, the smaller the surface area of each single electrode. The magnitude of inter-electrode capacitance is thus reduced resulting in a lower signal-to-noise ration of the obtainable signal [158]. 


\section{Electrical impedance tomography (EIT) - electrical resistance tomography (ERT)}

In the case of ERT, multiple electrodes are arranged around the periphery of a process vessel or a pipeline in such a way that they are in contact with the process fluid but do not disturb the process flow pattern. Between the electrode pairs a small alternating current is applied and voltage measurements are made between remaining electrode pairs according to a predefined measurement strategy. An image reconstruction algorithm is used to generate images of the distribution of materials within the sensing zone [159].

The most common electrode architecture is circumferential mounted electrodes, typically around a process vessel or pipeline. These circular pipeline-based sensors measure an entire cross-sectional volume. Linear sensors have also been demonstrated [160]. The work by Bolton and Primrose [160] presents a comprehensive overview on applications of ERT in the pharmaceutical industry.

Electrical resistance tomography is a relatively simple and cost-effective technique for measuring the distribution of electrical conductivity within multiphase systems. Examples include on-line measurement of solid distribution in stirred tanks and crystallizers, monitoring the performance of an industrial pressure filter, and also flow profile and velocity measurements in a physical model of a catalytic reactor [160]. The main limitation of ERT is that it cannot define the source of the conductivity change. A combination of ERT together with other technologies is recommended to further enhance its abilities and eliminate its limitations [161].

\subsubsection{Application examples}

Early work in the field of electrical capacitance tomography was published at the University of Manchester Institute of Science and Technology (UMIST) [162,163]. Since that time, several studies published the application of ECT for pneumatic dense-phase conveying, mainly to examine flow instabilities and mass flow rates [164-166]. More recently, a further attempt to apply ECT in pneumatic conveying was published [167], but this appeared to be limited to resolving fine porosity differences and did not investigate any material specific behaviour. With the aim to shed new light on the mechanisms of plug flow, Nied et al. [168] reported the use of electrical capacitance tomography to characterize the inner structure of plugs by measuring characteristic indicators such as the temporal and spatial void fraction profiles. Numerous applications of ECT for the monitoring and measuring of particulate processes are described in the literature. The work by Zhang et al. [169] presents a review on the application of ECT in 
particulate process measurement, including the monitoring of flow regime and solids distribution, solids flow velocity measurement, and fluidized bed dryers. Furthermore, the electrostatic phenomenon and the effects of electrostatics on the performance of ECT systems are discussed, as well as challenges of ECT for particulate process measurements. Figure 9 shows an example for application of ECT for gas-solids flow measurements, specifically the solids distribution in the conical section of a cyclone separator presented as 2D and 3D images [170]. Another example is provided by Ehrhardt et al. [171], in which the homogeneity of powder mixtures was assessed by on-line electrical capacitance. More recently, Rimpiläinen et al. [172] demonstrated the use of ECT as a monitoring tool for high-shear mixing and granulation. Mixing experiments and granulations were carried out using a vertical high-shear mixer equipped with a plastic three-blade impeller and the relative permittivity distribution of the powder bed at different process time points were acquired. ECT tomograms and mixing indices from these experiments were found to be useful tools for evaluating the characteristics of the materials both qualitatively and quantitatively. 

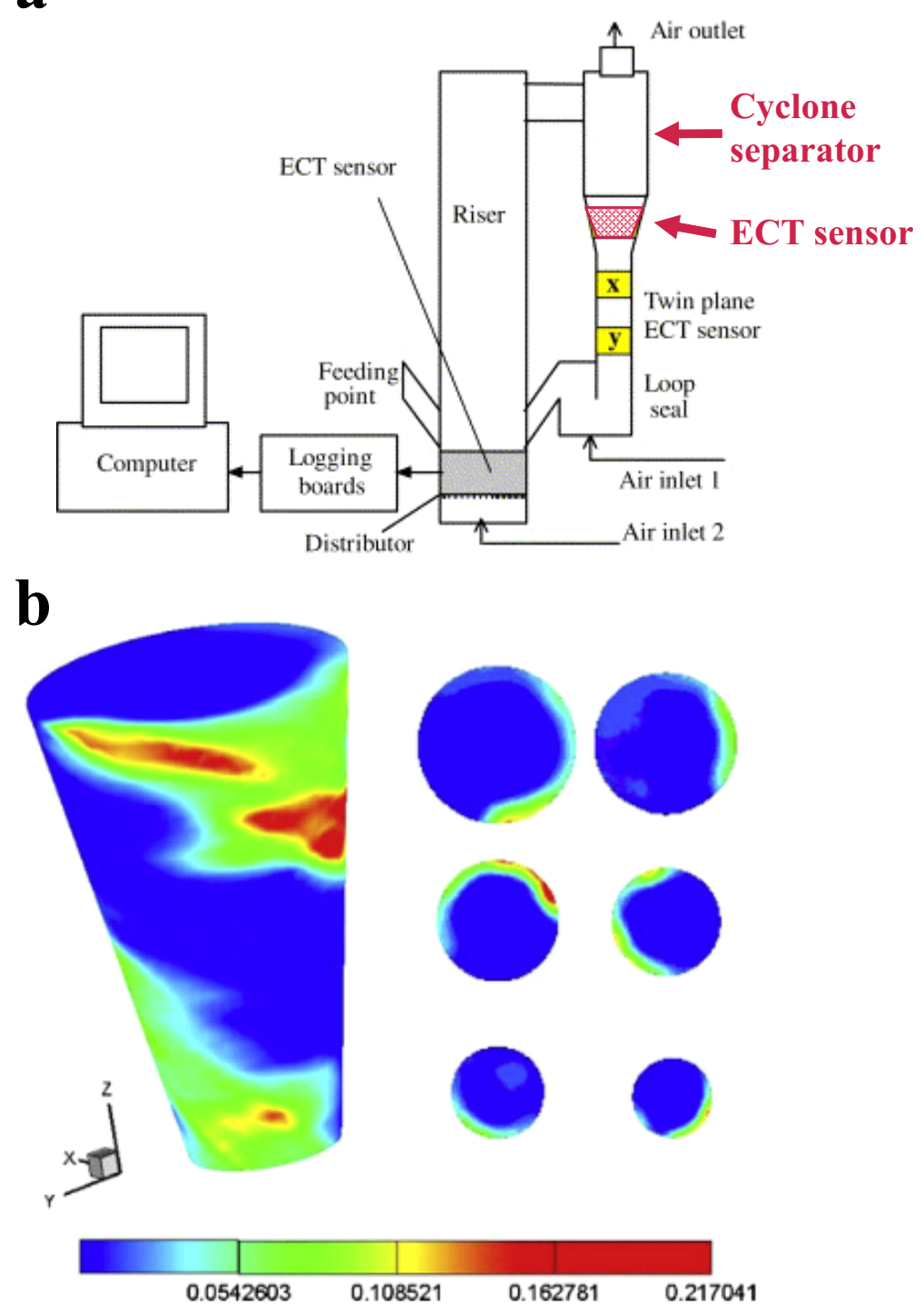

Figure 9: Example of ECT for gas-solids flow measurement in circulating fluidized beds: (a) System outline and experimental setup, and (b) solids' concentrations in the conical section of a cyclone separator presented as $2 \mathrm{D}$ and 3D images (Reprinted with modifications from [170] with permission from Elsevier).

Dyakowski et al. [173] reviewed the use of the electrical tomography method in monitoring and investigating gas-solids and liquid-solids flows. It has been concluded that ECT systems are suitable for monitoring dry or non-conducting systems, whereas ERT systems work best for wet or conducting systems. It has been emphasized, however, that this distinction currently has more of a historical character. Research in the area of multimodality concepts which incorporate both techniques in a single senor and measuring device, i.e., impedance measurements, aims to allow monitoring multiphase systems, irrespective of their electrical properties. Hence, both the electrical conductivity and the dielectric permittivity could be inferred from the measurements. A recent review by Yao and Takei [174] provides the latest development and emerging technologies on the application of process tomography to multiphase flow measurements as 
well as their challenges. In industrial applications ERT and ECT are described as being widely applied in multiphase flow measurements, and applications in particular for circulating fluidized bed, trickle-bed reactor and temperature measurements are discussed. For example, Ricard et al. [175] demonstrated the application of ERT for monitoring multiphase pharmaceutical processes. However, even though it has been demonstrated that the ERT system can provide very valuable information for the monitoring and control of multiphase processes relevant to the pharmaceutical industry, its main application is clearly on wet or conducting systems.

\subsection{X-ray techniques}

\subsubsection{Basic concept and instrumentation}

Electromagnetic waves of wavelengths between $0.01 \mathrm{~nm}$ to $10 \mathrm{~nm}$ are known as X-rays [176]. When an X-ray beam passes through a sample, different types of interactions can occur: photoelectric absorption, Compton scattering and Rayleigh scattering [177]. The transmitted modified X-rays are subsequently measured via a detector. A wide variety of X-ray detectors is available. Some of them counting single photons, some providing measurements of count rate or total flux, others measuring the energy, position, and/or the incidence time of each X-ray [178]. The absorption of X-rays by materials depends (among other quantities) on the elementary compositions and the material density $[179,180]$. Hence, density distributions within pharmaceutical powders and compacts can be studied [181]. The X-ray physics is described in detail in the handbook of X-ray spectroscopy by Grieken and Markowicz [182].

The most common X-ray technique is X-ray computed tomography (CT), where X-ray images are collected from multiple angles and the data is subsequently reconstructed to a three dimensional image. More precisely, X-rays are directed from a high-power source towards a sample, and a detector on the opposite side of the sample measures the intensity of the transmitted X-rays. Two-dimensional "shadow" images are then collected for various viewpoints by moving the sample relative to the X-ray beam. The two-dimensional images are subsequently combined to generate a complete three-dimensional map of the sample. The intensity of transmitted X-rays is controlled by the sample path length and the X-ray attenuation coefficient of the material that encounters on that path [183]. A longer path length and a higher attenuation coefficient of the material result in a greater number of diffraction and scattering events. Thus, a gray-scale in the images is provided by varying levels of signal intensity, which 
gives information about the density, thickness, and attenuation properties of the sample. The strongest contrast in the images are obtained for very dense or thick regions and areas that contain heavy elements (e.g., sodium, chlorine, or iron). X-ray CT can basically be regarded as creating a three-dimensional map of the relative atomic density of the sample under evaluation [184]. X-rays can easily penetrate all pharmaceutically relevant excipients while exhibiting negligible diffraction [185]. X-ray CT covers a range of spatial resolution, depending on sample size, of between several hundred nm to $100 \mu \mathrm{m}$ [186]. Such a high spatial resolution can be achieved due to the short wavelength of X-rays and the availability of suitable detector arrays. There is no clear distinction at what resolution the conventional CT ends and where X $\mu$ CT starts but it is suggested that any results with higher spatial resolution than $100 \mu \mathrm{m}$ should be regarded as $\mathrm{X} \mu \mathrm{CT}$ [186]. Moreover, in contrast to conventional CT, where X-ray source and detector are rotated around the sample object, the equipment used for modern $\mathrm{X} \mu \mathrm{CT}$ typically rotates the sample object while source and detector are kept stationary [185].

\subsubsection{Application examples}

X-rays offer promising applications for machine vision, giving information about the internal characteristics of an object being viewed. This method has already been in relatively extensive use in the field of non-destructive testing, for example analysis of the microstructure of polymer based composites [187], textile [188], woven composites attributed to their micro-structure $[189,190]$, inspecting cracks in steel welds of wet welded steel joint [191], and foreign body detection in food [192]. Recently, Wagner et al. [193] demonstrated the use of an X-ray system as an automated content testing system. An X-ray detection model was established which allowed the precise determination of the API content and content uniformity (of a powder mixture) inside capsules during a continuous capsule-filling process.

X-ray CT has also been extensively used in the field of pharmaceutical sciences. An overview of pharmaceutical applications of X-ray CT is provided by Hancock and Mullarney [184] and by Zeitler and Gladden [185]. More recently, in a comprehensive review by Dave et al. [89] Xray CT is described as an emerging technology for the non-invasive characterization of physical-mechanical properties of tablets. For example, Sinka et al. [194] utilized X-ray CT to quantitatively evaluate the variations in density in tablets by generating density maps. As shown in Figure 10, X-ray CT can provide cross-sectional images in different planes through a component in a non-destructive manner. Tablet A presents high density regions under the breakline and in the band area. For tablet B similar observations can be made, however, when compared with tablet A there is little evidence of dense regions below the break-line. From this 
data it becomes clear that the internal structure can be investigated with high resolution, therefore homogeneity, micro-porosity and potential cracks can be analyzed. To date, studies of pharmaceutical materials focus on off-line analysis. However, recent advances in X-ray CT technologies will bring this technique closer to the process and may enable in-line monitoring of density changes during manufacturing.

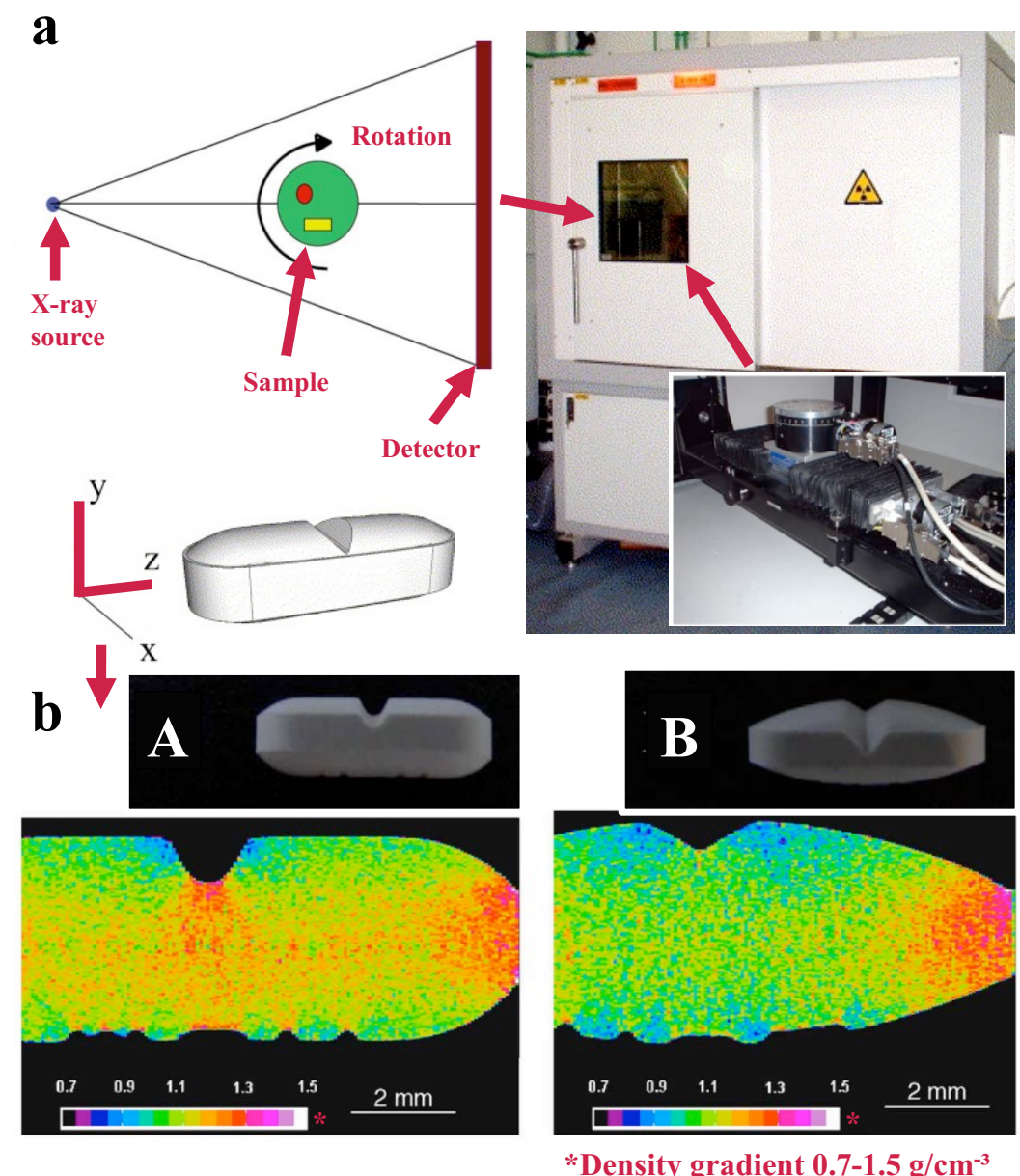

Figure 10: X-ray computed tomography $(C T)$ for measurements of density variations in tablets: (a) Schematic of an X-ray CT system with a cone-beam configuration (left) and photographs of a $225 \mathrm{kV}$ micro-focus X-ray cabinet system (right). This system includes a detector with a CCD camera to acquire radiography images. (b) Y-Z density distribution maps of two different tablet geometries (Reprinted with modifications from [194] with permission from Elsevier). 


\section{Summary and discussion}

The technologies presented in this review vary considerably in terms of acquisition and data processing time/effort, resolution and also in their cost/effort for system integration into a pharmaceutical manufacturing line. An overview of the key performance characteristics and related advantages and disadvantages of each method in the form of a SWOT (strengths, weaknesses, opportunities, and threats) analysis is provided in Table 2.

In the context of technologies which utilize the interaction of electromagnetic radiations (NIRS, NIR-CI, THz spectroscopy and imaging, X-ray based methods, microwave) with matter, the potential of described methods for real time monitoring of powder density differ. The wide variety of studies mentioned in the published reviews reflect the usefulness of NIR as a potential non-destructive analytical tool to analyze density variations within a particulate matter. In recent years, the terahertz technology has also experienced wide popularity in the pharmaceutical industry. The rapid drive to develop and apply this technology in the past few years has led to a number of promising applications. However, further development is required to make it a robust process sensor for in-line powder density monitoring. XCT can provide quantitative information of variations in density in tablets by generating density maps. However, depending on the sample size and desired resolution, those measurements can take minutes to hours. Technologies that utilize the interaction of sound waves (ultrasonic, acoustic emission $(\mathrm{AE})$ ) with matter show clear potential for real-time powder density measurement technique. In terms of electrical tomography, a technology which utilizes the interaction of electrical current with matter, the huge amount of information to be processed along with the low to moderate resolution and the need for inherent material properties (i.e., non-conducting substances for ECT and conducting substances for ERT) may be the most relevant aspects that have so far limited a wider application of this technology as a PAT in pharmaceutical research and manufacturing. 
Table 2: Method assessment (provided data/information was extracted from articles described in section 4).

\begin{tabular}{|c|c|c|c|}
\hline Technique & $\begin{array}{l}\text { Data acquisition and } \\
\text { processing time/effort }\end{array}$ & Resolution & $\begin{array}{l}\text { Effort for system } \\
\text { integration into a } \\
\text { pharmaceutical line }\end{array}$ \\
\hline $\begin{array}{l}\text { Near-infrared } \\
\text { spectroscopy } \\
\text { (NIRS) and NIR } \\
\text { chemical imaging } \\
\text { (NIR-CI) }\end{array}$ & $\begin{array}{l}\text { Strengths: } \\
\text { - NIR bands are highly } \\
\text { sensitive and respond } \\
\text { to the physical and } \\
\text { chemical } \\
\text { characteristics of the } \\
\text { analyte (investigation } \\
\text { of high absorption } \\
\text { and/or scattering } \\
\text { properties e.g. solids } \\
\text { possible) } \\
\text { Fast information about } \\
\text { the average density } \\
\text { Weaknesses: } \\
\text { NIR spectra are broad } \\
\text { and consist of } \\
\text { overlapping and fused } \\
\text { peaks } \\
\text { In order to extract } \\
\text { meaningful } \\
\text { information, NIR } \\
\text { spectra require data } \\
\text { processing; } \\
\text { development of } \\
\text { chemometric models } \\
\text { requires reference } \\
\text { analytics }\end{array}$ & $\begin{array}{l}\text { The method cannot be } \\
\text { more accurate than the } \\
\text { analytical reference } \\
\text { method used to } \\
\text { calibrate the } \\
\text { chemometric model. } \\
\text { - Can only accurately } \\
\text { measure the outer 1- } \\
2 \text { mm layer of material } \\
\text { because of the limited } \\
\text { penetration depth } \\
\text { - Scattering effects can } \\
\text { introduce errors in the } \\
\text { density measurement }\end{array}$ & $\begin{array}{l}\text { Opportunities for } \\
\text { implementation: } \\
\text { - } \\
\text { Non-destructive and } \\
\text { contactless technique } \\
\text { Robustness and } \\
\text { flexibility (in-line, at- } \\
\text { line or off-line) } \\
\text { - Simplicity in use, } \\
\text { minimal training and } \\
\text { supervision required } \\
\text { Most new NIR } \\
\text { instruments are highly } \\
\text { portable, saving time } \\
\text { and labor } \\
\text { Most samples can be } \\
\text { presented for analysis in } \\
\text { "as is" physical form } \\
\text { (practically eliminating } \\
\text { the elaborate sample } \\
\text { preparation) } \\
\text { - } \text { Is among the most } \\
\text { commonly used } \\
\text { analytical tools in the } \\
\text { pharmaceutical } \\
\text { development (many } \\
\text { sized tablet batches } \\
\text { applications examples } \\
\text { available) } \\
\text { implementation: } \\
\text { Development of a } \\
\text { robust calibration model } \\
\text { challenging. Any } \\
\text { changes in the system, } \\
\text { or occurrence of an } \\
\text { unknown variable can } \\
\text { be deleterious to the } \\
\text { reliability of the model. } \\
\text { - }\end{array}$ \\
\hline Technique & $\begin{array}{l}\text { Data acquisition and } \\
\text { processing time/effort }\end{array}$ & Resolution & $\begin{array}{l}\text { Effort for system } \\
\text { integration into a } \\
\text { pharmaceutical line }\end{array}$ \\
\hline Ultrasonic method & $\begin{array}{l}\text { Strengths: } \\
\text { - Short measurement } \\
\text { time } \\
\text { - Method does not } \\
\text { require a calibration } \\
\text { model } \\
\text { Weaknesses: }\end{array}$ & $\begin{array}{l}\text { Low to moderate } \\
\text { spatial resolution } \\
\text { - High noise level due } \\
\text { to interface changes } \\
\text { (particle and air) } \\
\text { - A typical ultrasonic } \\
\text { image has a low } \\
\text { signal-to-noise ratio }\end{array}$ & $\begin{array}{l}\text { Opportunities for } \\
\text { implementation: } \\
\text { - } \quad \text { Non-destructive } \\
\text { technique } \\
\text { - No need for an optical } \\
\text { transparent window } \\
\text { - Correlation between } \\
\text { local mechanical }\end{array}$ \\
\hline
\end{tabular}




\begin{tabular}{|c|c|c|c|}
\hline & $\begin{array}{l}\text { Skilled operator for } \\
\text { interpretation of data } \\
\text { needed }\end{array}$ & $\begin{array}{l}\text { (interpretation of the } \\
\text { image tends to be } \\
\text { subjective) } \\
\text { - Substances with good } \\
\text { acoustic properties } \\
\text { required }\end{array}$ & $\begin{array}{l}\text { hardness (i.e., local } \\
\text { Young's modulus) and } \\
\text { local density in a tablet } \\
\text { by ultrasonics } \\
\text { - Method is relatively } \\
\text { economical } \\
\text { - Contactless } \\
\text { measurement (in the } \\
\text { case of air-coupled } \\
\text { ultrasonics) } \\
\text { - No sample preparation } \\
\text { required } \\
\text { Threats / Challenges for } \\
\text { implementation: } \\
\text { - Need for a medium to } \\
\text { conduct the acoustic } \\
\text { wave into the compact, } \\
\text { unless the air-coupled } \\
\text { ultrasonic method is } \\
\text { used } \\
\text { For air-coupled } \\
\text { ultrasonics, separate } \\
\text { transmit and receive } \\
\text { transducers required }\end{array}$ \\
\hline Technique & $\begin{array}{l}\text { Data acquisition and } \\
\text { processing time/effort }\end{array}$ & Resolution & $\begin{array}{l}\text { Effort for system } \\
\text { integration into a } \\
\text { pharmaceutical line }\end{array}$ \\
\hline $\begin{array}{l}\text { Acoustic emission } \\
\text { (AE) technique }\end{array}$ & $\begin{array}{l}\text { Strengths: } \\
\text { - Signal can be detected } \\
\text { from one specific } \\
\text { location } \\
\text { - High sensitivity to } \\
\text { particle impact in the } \\
\text { vicinities of the sensor } \\
\text { Weaknesses: } \\
\text { - Expertise for handling } \\
\text { and processing of data } \\
\text { required } \\
\text { As an indirect method } \\
\text { it requires } \\
\text { sophisticated } \\
\text { multivariate modeling } \\
\text { to analyze obtained } \\
\text { data } \\
\text { Multiple physical } \\
\text { sources could lead to } \\
\text { the generation of AE } \\
\text { noise that could be } \\
\text { challenging to resolve } \\
\text { and interpret } \\
\text { AE is dominated by } \\
\text { collisions of particles } \\
\text { with the vessel wall } \\
\text { and as such will only } \\
\text { be indicative of } \\
\text { changes in powder } \\
\text { composition at this } \\
\text { interface, rather than in }\end{array}$ & $\begin{array}{l}\text { Physical changes } \\
\text { during processing may } \\
\text { not generate detectable } \\
\text { waves over the applied } \\
\text { frequency range }\end{array}$ & $\begin{array}{l}\text { Opportunities for } \\
\text { implementation: } \\
\text { - Non-destructive and } \\
\text { contactless technique } \\
\text { - No need for an optical } \\
\text { transparent window } \\
\text { - Easy to set up } \\
\text { instrumentation } \\
\text { - Allows its use in harsh } \\
\text { process conditions such } \\
\text { as high pressures and } \\
\text { temperatures } \\
\text { Threats / Challenges for } \\
\text { implementation: } \\
\text { - Acoustic measurements } \\
\text { in the audible range } \\
\text { makes it potentially } \\
\text { prone to signal } \\
\text { contamination from } \\
\text { other sound sources } \\
\text { In an industrial } \\
\text { environment, and the } \\
\text { use of wavelet } \\
\text { decomposition makes it } \\
\text { computationally heavy }\end{array}$ \\
\hline
\end{tabular}




\begin{tabular}{|c|c|c|c|}
\hline & the bulk material & & \\
\hline Technique & $\begin{array}{l}\text { Data acquisition and } \\
\text { processing time/effort }\end{array}$ & Resolution & $\begin{array}{l}\text { Effort for system } \\
\text { integration into a } \\
\text { pharmaceutical line }\end{array}$ \\
\hline $\begin{array}{l}\text { Terahertz } \\
\text { spectroscopy and } \\
\text { terahertz imaging }\end{array}$ & $\begin{array}{l}\text { Strengths: } \\
\text { - Acquisition time can } \\
\text { be }<30 \mathrm{~ms} \\
\text { - No complex calibration } \\
\text { of chemometric models } \\
\text { is needed prior to the } \\
\text { analysis } \\
\text { Weaknesses: } \\
\text { - A model relating the } \\
\text { measured effective } \\
\text { refractive index to the } \\
\text { powder density has to } \\
\text { be developed }\end{array}$ & $\begin{array}{l}\text { Resolution is material } \\
\text { dependent (scattering } \\
\text { issues); scattering } \\
\text { effects in terahertz } \\
\text { measurements need to } \\
\text { be fully understood } \\
\text { and considered } \\
\text { - High penetration } \\
\text { power allows deep } \\
\text { probing of the } \\
\text { structure of solid } \\
\text { dosage forms, it has } \\
\text { high sensitivity to } \\
\text { small changes in the } \\
\text { refractive index as } \\
\text { well as the physical- } \\
\text { chemical attributes of } \\
\text { the samples } \\
\text { Relatively high } \\
\text { wavelength, i.e. spatial } \\
\text { resolution limits }\end{array}$ & $\begin{array}{l}\text { Opportunities for } \\
\text { implementation: } \\
\text { - Non-destructive and } \\
\text { contactless technique } \\
\text { - Fast, potential for } \\
\text { process analytics (at- } \\
\text { line, on-line or even in- } \\
\text { line application) } \\
\text { - Possibility to perform } \\
\text { the measurement at } \\
\text { high temperature due to } \\
\text { its insensibility to } \\
\text { thermal interference } \\
\text { Threats / Challenges for } \\
\text { implementation: } \\
\text { - Sample volume is } \\
\text { limited by the spot size } \\
\text { of the terahertz beam } \\
\text { (typically between } \\
1 \text { mm and } 2 \text { mm in } \\
\text { diameter) } \\
\text { Increase of robustness } \\
\text { for process integration }\end{array}$ \\
\hline Technique & $\begin{array}{l}\text { Data acquisition and } \\
\text { processing time/effort }\end{array}$ & Resolution & $\begin{array}{l}\text { Effort for system } \\
\text { integration into a } \\
\text { pharmaceutical line }\end{array}$ \\
\hline $\begin{array}{l}\text { Microwave } \\
\text { technique }\end{array}$ & $\begin{array}{l}\text { Strengths: } \\
\text { - Short measurement } \\
\text { time (seconds) } \\
\text { Weaknesses: } \\
\text { - Data analysis and } \\
\text { interpretation may be } \\
\text { difficult } \\
\text { - Simultaneous existence } \\
\text { of several variables } \\
\text { affecting the } \\
\text { microwave } \\
\text { measurement } \\
\text { (temperature, density, } \\
\text { moisture, structure, } \\
\text { etc.) }\end{array}$ & $\begin{array}{l}\text { Very low resolution } \\
\text { (cm range) } \\
\text { High amount of } \\
\text { scattering at boundary } \\
\text { layers }\end{array}$ & $\begin{array}{l}\text { Opportunities for } \\
\text { implementation: } \\
\text { - Non-destructive and } \\
\text { contactless technique } \\
\text { - Easy to set up } \\
\text { instrumentation; can be } \\
\text { used without contact } \\
\text { even over bigger } \\
\text { distances } \\
\text { - No need for an optical } \\
\text { transparent window } \\
\text { - Antennas can be non- } \\
\text { contacting antennas } \\
\text { - Cost effective } \\
\text { technology } \\
\text { - Capable of analyzing } \\
\text { small and large volumes } \\
\text { of samples } \\
\text { Threats / Challenges for } \\
\text { implementation: } \\
\text { - Usual application only } \\
\text { for moisture detection }\end{array}$ \\
\hline Technique & $\begin{array}{l}\text { Data acquisition and } \\
\text { processing time/effort }\end{array}$ & Resolution & $\begin{array}{l}\text { Effort for system } \\
\text { integration into a }\end{array}$ \\
\hline
\end{tabular}




\begin{tabular}{|c|c|c|c|}
\hline & & & pharmaceutical line \\
\hline $\begin{array}{l}\text { Electrical } \\
\text { tomography }\end{array}$ & $\begin{array}{l}\text { Strengths: } \\
\text { - Fast imaging speed } \\
\text { (typically } 100 \\
\text { frames/s) } \\
\text { Weaknesses: } \\
\text { - Increased } \\
\text { computational effort } \\
\text { (soft field technology) }\end{array}$ & $\begin{array}{l}\text { - The resolution limit is } \\
\text { in the mm range } \\
\text { - Significant differences } \\
\text { in the dielectric } \\
\text { constant needed } \\
\text { - Electrical capacitance } \\
\text { tomography (ECT) } \\
\text { only applicable to the } \\
\text { imaging of non- } \\
\text { conducting substances } \\
\text { - Electrical resistance } \\
\text { tomography (ERT) } \\
\text { only applicable to the } \\
\text { imaging of conducting } \\
\text { substances }\end{array}$ & $\begin{array}{l}\text { Opportunities for } \\
\text { implementation: } \\
\text { - Non-destructive and } \\
\text { contactless technique } \\
\text { - No need for an optical } \\
\text { transparent window } \\
\text { - Low investment costs } \\
\text { - In ECT installation of } \\
\text { multiple sensors to } \\
\text { provide cross-sectional } \\
\text { view of a powder } \\
\text { stream in a vessel } \\
\text { - Can withstand high } \\
\text { pressure (up to } 150 \text { bar) } \\
\text { and high temperature } \\
\text { (up to } 300^{\circ} \mathrm{C} \text { ) } \\
\text { Threats / Challenges for } \\
\text { implementation: } \\
\text { - The huge amount of } \\
\text { information must be } \\
\text { contrasted with the low } \\
\text { resolution } \\
\text { In ERT electrodes need } \\
\text { to be directly in touch } \\
\text { with sample }\end{array}$ \\
\hline Technique & $\begin{array}{l}\text { Data acquisition and } \\
\text { processing time/effort }\end{array}$ & Resolution & $\begin{array}{l}\text { Effort for system } \\
\text { integration into a } \\
\text { pharmaceutical line }\end{array}$ \\
\hline X-ray methods & $\begin{array}{l}\text { Strengths: } \\
\text { - Qualitative and } \\
\text { quantitative } \\
\text { information about the } \\
\text { structure of } \\
\text { pharmaceutical dosage } \\
\text { forms (2D and 3D } \\
\text { information) } \\
\text { Weaknesses: } \\
\text { - Time-consuming } \\
\text { image acquisition and } \\
\text { analysis (minutes to } \\
\text { hours) } \\
\text { Correlation of image } \\
\text { pixel values to the } \\
\text { solid-fraction of the } \\
\text { sample requires post- } \\
\text { processing } \\
\text { Managing the large } \\
\text { amount of data and } \\
\text { selecting the best } \\
\text { parameters for each } \\
\text { sample may be } \\
\text { challenging } \\
\text { Image segmentation } \\
\text { can be challenging }\end{array}$ & $\begin{array}{l}\text { - High spatial resolution } \\
\text { - High penetration } \\
\text { power } \\
\text { - Low atomic number } \\
\text { substances and object } \\
\text { thickness and enlarged } \\
\text { field size can increase } \\
\text { scattering } \\
\text { - Only materials with } \\
\text { high density or high } \\
\text { atomic number } \\
\text { detectable }\end{array}$ & $\begin{array}{l}\text { Opportunities for } \\
\text { implementation: } \\
\text { - Non-destructive and } \\
\text { contactless technique } \\
\text { - No need for an optical } \\
\text { transparent window } \\
\text { - New X-ray technologies } \\
\text { will enable at-line, on- } \\
\text { line or even in-line } \\
\text { applications } \\
\text { Threats / Challenges for } \\
\text { implementation: } \\
\text { - Sample size is limited } \\
\text { by the machine size } \\
\text { - Typically applied in off- } \\
\text { line mode } \\
\text { Caution needs to be } \\
\text { exercised during the } \\
\text { analysis of } \\
\text { multicomponent } \\
\text { systems since the linear } \\
\text { attenuation of the } \\
\text { material analyzed by X- } \\
\text { ray CT depends not } \\
\text { only on the material } \\
\text { density but also on the } \\
\text { atomic number of the }\end{array}$ \\
\hline
\end{tabular}




\section{Conclusions and future perspectives}

Continuous and efficient monitoring of powder density variations in a manufacturing line is of great importance in the development and manufacturing of high-quality end products consisting of particulate matter. Consistent technological progress and developments in the field of nondestructive technologies encourage this vision. The appropriate method should be selected in terms of efficiency, safety and costs for their specific application. As in some complex cases, no single technique is applicable, emerging tools based on combined physical principles endow promises. Moreover, the broad range of available PAT methods and concepts that are applicable for powder density monitoring, most of which developed for research environments, need further development in order to be suitable as robust sensors in an industrial setting. The evolving framework of PAT-enabled and model-informed pharmaceutical product manufacturing will necessitate a suitably sophisticated and correct expertise set. This will require the ability to integrate powder dynamics sensing technologies (e.g. sensor accuracy and robustness checks, software and hardware maintenance) and the material/process models involved (e.g. model maintenance, re-calibrate for varying raw materials, transfer PAT methods from one manufacturing site to another).

Emerging experimental methods and advanced modeling approaches will need to be interlinked to improve the understanding of the relationship between material attributes, process settings $\&$ design and the density of the powder and the drug product. Coupling simulations with advanced process analytical technologies (Figure 11) has the potential to provide new insights into density distributions at various critical stages in a process stream. 3D density distributions generated by high fidelity simulations paired with PAT sensor data has the ability to provide 1) a simulation-assisted optimization of the PAT sensor location in a process, and 2) the extraction of additional information related to critical quality attributes as it was demonstrated for the monitoring and simulation of a coating process [195]. This is particularly critical for continuous manufacturing in order to optimize processes and formulations and ultimately improve the quality of drug products.

There are still some challenges to overcome, but the increased knowledge generated from PAT applicable for monitoring powder density during different unit operations and for a wide diversity of drug products can be expected to act as a catalyst for further development and implementation of innovative pharmaceutical development, manufacturing, and quality assurance strategies. 


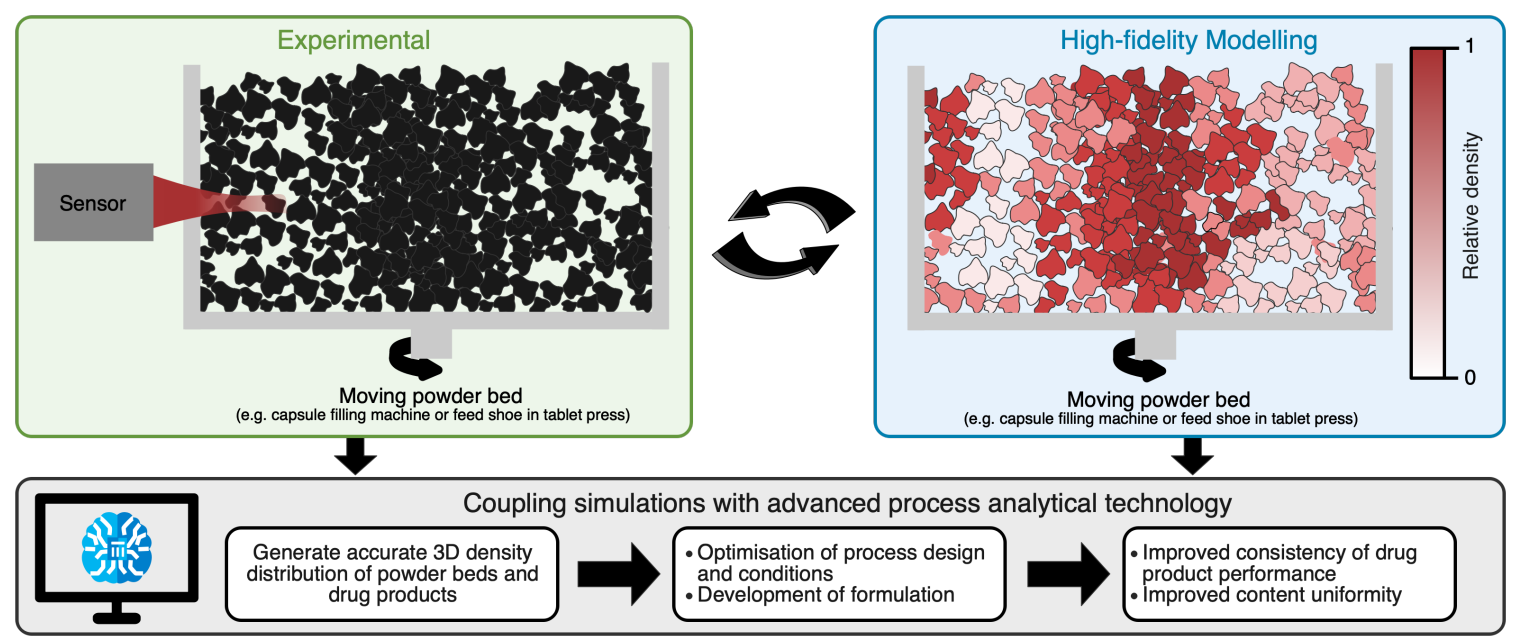

Figure 11: Future perspective into linking advanced process analytical technologies with high-fidelity simulations to generate accurate $3 \mathrm{D}$ density distributions of key stages in a pharmaceutical manufacturing line.

\section{Declaration of competing interest}

The authors declare no known competing financial interests or personal relationships related to the work reported in this paper.

\section{Acknowledgments}

This work has been funded by the Austrian COMET Program under the auspices of the Austrian Federal Ministry of Transport, Innovation and Technology (bmvit), the Austrian Federal Ministry of Economy, Family and Youth (bmwfj) and by the State of Styria (Styrian Funding Agency SFG). COMET is managed by the Austrian Research Promotion Agency FFG.

\section{References}

[1] B.C. Hancock, J.T. Colvin, M.P. Mullarney, A.V. Zinchuk, The relative densities of pharmaceutical powders, blends, dry granulations and immediate-release tablets, Pharm. Technol. 27 (2003) 64-80.

[2] G. Nebgen, D. Gross, V. Lehmann, F. Müller, 1H-NMR microscopy of tablets, J. Pharm. Sci. 84 (1995) 283-291.

[3] P.J. Cullen, Food mixing: Principles and applications, John Wiley \& Sons, 2009.

[4] J. Prescott, R. Barnum, On powder flowability, Pharm. Technol. 24 (2000) 60-84.

[5] J.K. Prescott, Maintaining product uniformity and uninterrupted flow to directcompression tableting presses, Pharm. Technol. 18 (1994) 99-114.

[6] D. Markl, J.A. Zeitler, A review of disintegration mechanisms and measurement techniques, Pharm. Res. 34 (2017) 890-917.

[7] M. Leane, K. Pitt, G. Reynolds, T. Manufacturing, C. System, M.C.S. Working, A proposal for a drug product Manufacturing Classification System (MCS) for oral solid 
dosage forms, Pharm. Dev. Technol. 00 (2014) 1-10.

[8] J.M.S. Negre, E.G. Montoya, P.P. Lozano, J.E.A. Díaz, M.R. Carreras, R.F. García, M.M. Carmona, J.R.T. Grau, SeDeM Diagram : A New Expert System for the Formulation of Drugs in Solid Form, Expert Syst. Human, Mater. Autom. (2011) 17-34.

[9] W.K. Hsiao, T.R. Hörmann, P. Toson, A. Paudel, P. Ghiotti, F. Stauffer, F. Bauer, S. Lakio, O. Behrend, R. Maurer, J. Holman, J. Khinast, Feeding of particle-based materials in continuous solid dosage manufacturing: a material science perspective, Drug Discov. Today. 25 (2020) 800-806.

[10] S. van den Ban, D.J. Goodwin, The impact of granule density on tabletting and pharmaceutical product performance, Pharm. Res. 34 (2017) 1002-1011.

[11] R. Singh, A.D. Román-Ospino, R.J. Romañach, M. Ierapetritou, R. Ramachandran, Real time monitoring of powder blend bulk density for coupled feed-forward/feed-back control of a continuous direct compaction tablet manufacturing process, Int. J. Pharm. 495 (2015) 612-625.

[12] D. Markl, M. Warman, M. Dumarey, E. Bergman, S. Folestad, Z. Shi, L. Francis, D.J. Goodwin, J.A. Zeitler, Review of real-time release testing of pharmaceutical tablets : State-of-the art, challenges and future perspective, Int. J. Pharm. 582 (2020) 119353.

[13] D. Markl, J. Sauerwein, D.J. Goodwin, S. van den Ban, J.A. Zeitler, Non-destructive determination of disintegration time and dissolution in immediate release tablets by terahertz transmission measurements, Pharm. Res. 34 (2017) 1012-1022.

[14] B.E. Jones, The filling of powders into two-piece hard capsules, Int. J. Pharm. 227 (2001) 5-26.

[15] E. Faulhammer, M. Llusa, C. Radeke, O. Scheibelhofer, S. Lawrence, S. Biserni, V. Calzolari, J.G. Khinast, The effects of material attributes on capsule fill weight and weight variability in dosator nozzle machines, Int. J. Pharm. 471 (2014) 332-338.

[16] J.T. Pinto, S. Stranzinger, A. Kruschitz, E. Faulhammer, S. Stegemann, E. Roblegg, A. Paudel, Insights into the processability and the performance of adhesive blends of inhalable jet-milled and spray dried salbutamol sulphate at low and high loads, Int. J. Pharm. 48 (2018) 466-477.

[17] E. Faulhammer, S. Zellnitz, T. Wutscher, S. Stranzinger, A. Zimmer, A. Paudel, Performance indicators for carrier-based DPIs: Carrier surface properties for capsule filling and API properties for in vitro aerosolisation, Int. J. Pharm. 536 (2018) 326-335.

[18] E. Faulhammer, M. Llusa, P.R. Wahl, A. Paudel, S. Lawrence, S. Biserni, V. Calzolari, J.G. Khinast, Development of a design space and predictive statistical model for capsule filling of low-fill-weight inhalation products, Drug Dev. Ind. Pharm. 42 (2015) 221-230.

[19] S. Stranzinger, E. Faulhammer, O. Scheibelhofer, V. Calzolari, S. Biserni, A. Paudel, J.G. Khinast, Study of a Low-dose Capsule Filling Process by Dynamic and Static Tests for Advanced Process Understanding, Int. J. Pharm. 540 (2018) 22-30.

[20] P. Loidolt, S. Madlmeir, J.G. Khinast, Mechanistic modeling of a capsule filling process, Int. J. Pharm. 532 (2017) 47-54.

[21] S. Stranzinger, E. Faulhammer, J. Li, R. Dong, J.A. Zeitler, S. Biserni, V. Calzolari, J.G. Khinast, D. Markl, Predicting capsule fill weight from in-situ powder density measurements using terahertz reflection technology, Int. J. Pharm. 1 (2018) 100004.

[22] USP <699> Density of solids, in: United States Pharmacopeia, USP43-NF38 - 6938 (Pharmacopeial, United States Conv. Inc., Rockville, MD), 2020.

[23] ASTM Standard Test Method for Tap Density of Powders of Refractory Metals and Compounds by Tap-Pak Volumeter, in: Am. Soc. Test. Mater. West Conshohocken, PA, 1985.

[24] ASTM Standard Test Method for Mechanically Tapped Packing Density of Formed Catalyst and Catalyst Carriers, in: Am. Soc. Test. Mater. West Conshohocken, PA, 1988.

[25] USP <616> Bulk density and tapped density, in: United States Pharmacopeia, USP43- 
NF38 - 6850 (Pharmacopeial, United States Conv. Inc., Rockville, MD), 2020.

[26] E. Pharmacopeia, Chapter 2.9.34. "Bulk density and tapped density of powders," in: Eur. Pharmacop. 7.0, 2010.

[27] ASTM Standard Guide on Sampling for Process Analytical Technology, in: Am. Soc. Test. Mater. West Conshohocken, PA, 2018.

[28] P. Gy, Sampling of discrete materials - a new introduction to the theory of sampling: I. Qualitative approach, Chemom. Intell. Lab. Syst. 74 (2004) 7-24.

[29] K.H. Esbensen, Introduction to the theory and practice of sampling, in: TOS Forum, IM Publications Open, 2020.

[30] FDA, Guidance for Industry Guidance for Industry PAT — A Framework for Innovative Pharmaceutical, (2004) 19.

[31] ICH, ICH Q8(R2) (Pharmaceutical Development), ICH Q9 (Quality Risk Management), ICH Q10 (Pharmaceutical Quality System) and ICH Q11 (Development and Manufacture of Drug Substances).

[32] P. McKenzie, S. Kiang, J. Tom, A.E. Rubin, M. Futran, Can pharmaceutical process development become high tech?, AIChE J. 52 (2006) 3990-3994.

[33] S. Buchholz, Future manufacturing approaches in the chemical and pharmaceutical industry, Chem. Eng. Process. Process Intensif. 49 (2010) 993-995.

[34] G. Subramanian, Continuous Processing in Pharmaceutical Manufacturing, 2013.

[35] P. Poechlauer, J. Manley, R. Broxterman, B. Gregertsen, M. Ridemark, Continuous processing in the manufacture of active pharmaceutical ingredients and finished dosage forms: an industry perspective, Org. Process Res. Dev. 16 (2012) 1586-1590.

[36] A.U. Vanarase, M. Alcalà, J.I. Jerez Rozo, F.J. Muzzio, R.J. Romañach, Real-time monitoring of drug concentration in a continuous powder mixing process using NIR spectroscopy, Chem. Eng. Sci. 65 (2010) 5728-5733.

[37] E. Pharmacopeia, Chapter 5.25 "PAT - Process analytical technology," in: Eur. Pharmacop. 10th Ed., 2020.

[38] H. Wu, M.A. Khan, Quality-by-design (QbD): an integrated approach for evaluation of powder blending process kinetics and determination of powder blending end-point, J. Pharm. Sci. 98 (2009) 2784-2798.

[39] D. Markl, A. Strobel, R. Schlossnikl, J. Bøtker, P. Bawuah, C. Ridgway, J. Rantanen, T. Rades, P. Gane, K.-E. Peiponen, J.A. Zeitler, Characterisation of pore structures of pharmaceutical tablets: a review, Int. J. Pharm. 538 (2018) 188-214.

[40] L.M. Anovitz, D.R. Cole, Characterization and analysis of porosity and pore structures, Rev. Mineral. Geochemistry. 80 (2015) 61-164.

[41] ASTM Standard Practice for Near Infrared Qualitative Analysis, in: Am. Soc. Test. Mater. West Conshohocken, PA, 2016.

[42] H.W. Siesler, Y. Ozaki, S. Kawata, H.M. Heise, Near-infrared spectroscopy: principles, instruments, applications, John Wiley \& Sons, 2008.

[43] G. Reich, Near-infrared spectroscopy and imaging: Basic principles and pharmaceutical applications, Adv. Drug Deliv. Rev. 57 (2005) 1109-1143.

[44] K. Korasa, F. Vrečer, Overview of PAT process analysers applicable in monitoring of film coating unit operations for manufacturing of solid oral dosage forms, Eur. J. Pharm. Sci. 111 (2018) 278-292.

[45] O. Scheibelhofer, D.M. Koller, P. Kerschhaggl, J.G. Khinast, Continuous powder flow monitoring via near-infrared hyperspectral imaging, 2012 IEEE I2MTC - Int. Instrum. Meas. Technol. Conf. Proc. (2012) 748-753.

[46] B. Igne, S. Talwar, H. Feng, J.K. Drennen, C.A. Anderson, Near-Infrared Spatially Resolved Spectroscopy for Tablet Quality Determination, J. Pharm. Sci. 104 (2015) 4074-4081.

[47] V.S. Dave, H.I. Shahin, S.R. Youngren-Ortiz, M.B. Chougule, R. V. Haware, Emerging 
technologies for the non-invasive characterization of physical-mechanical properties of tablets, Int. J. Pharm. 532 (2017) 299-312.

[48] Y. Ozaki, C.W. Huck, K.B. Beć, Near-IR Spectroscopy and Its Applications, Mol. Laser Spectrosc. (2018) 11-38.

[49] M. Jamrógiewicz, Application of the near-infrared spectroscopy in the pharmaceutical technology, J. Pharm. Biomed. Anal. 66 (2012) 1-10.

[50] T. De Beer, a. Burggraeve, M. Fonteyne, L. Saerens, J.P. Remon, C. Vervaet, Near infrared and Raman spectroscopy for the in-process monitoring of pharmaceutical production processes, Int. J. Pharm. 417 (2011) 32-47.

[51] C.D. Ellison, B.J. Ennis, M.L. Hamad, R.C. Lyon, Measuring the distribution of density and tabletting force in pharmaceutical tablets by chemical imaging, J. Pharm. Biomed. Anal. 48 (2008) 1-7.

[52] N. Souihi, D. Nilsson, M. Josefson, J. Trygg, Near-infrared chemical imaging (NIR-CI) on roll compacted ribbons and tablets - multivariate mapping of physical and chemical properties, Int. J. Pharm. 483 (2015) 200-211.

[53] M. Khorasani, J.M. Amigo, J. Sonnergaard, P. Olsen, P. Bertelsen, J. Rantanen, Visualization and prediction of porosity in roller compacted ribbons with near-infrared chemical imaging (NIR-CI), J. Pharm. Biomed. Anal. 109 (2015) 11-17.

[54] M. Khorasani, J.M. Amigo, P. Bertelsen, C.C. Sun, J. Rantanen, Process optimization of dry granulation based tableting line: Extracting physical material characteristics from granules, ribbons and tablets using near-IR (NIR) spectroscopic measurement, Powder Technol. 300 (2016) 120-125.

[55] A.D. Román-Ospino, R. Singh, M. Ierapetritou, R. Ramachandran, R. Méndez, C. Ortega-Zuñiga, F.J. Muzzio, R.J. Romañach, Near infrared spectroscopic calibration models for real time monitoring of powder density, Int. J. Pharm. 512 (2016) 61-74.

[56] C C. Ortega-Zúñiga, C.P. De la Rosa, A.D. Román-Ospino, A. Serrano-Vargas, R.J. Romañach, R. Méndez, Development of near infrared spectroscopic calibration models for in-line determination of low drug concentration, bulk density, and relative specific void volume within a feed frame, J. Pharm. Biomed. Anal. 164 (2019) 211-222.

[57] J. Blitz, G. Simpson, Ultrasonic methods of non-destructive testing, Springer Science \& Business Media, 1995.

[58] J.T. Leskinen, Acoustic Techniques for Pharmaceutical Process Monitoring, Acad. Diss. Univ. East. Finland, Kuopio, Finl. (2013).

[59] V. Mohammadi, M. Ghasemi-Varnamkhasti, L.A. González, Analytical measurements of ultrasound propagation in dairy products: A review, Trends Food Sci. Technol. 61 (2017) $38-48$.

[60] D.J. McClements, Food emulsions: principles, practices, and techniques, CRC press, 2015.

[61] W.M. Carey, R.B. Evans, Ocean ambient noise: measurement and theory, Springer Science \& Business Media (2011).

[62] W.A. Grandia, C.M. Fortunko, NDE applications of air-coupled ultrasonic transducers, in: 1995 IEEE Ultrason. Symp. Proceedings. An Int. Symp. Vol. 1. (1995) 697-709.

[63] J.P. Monchalin, Non contact generation and detection of ultrasound with lasers, in: Proceedings of the 16th World Conf. Nondestruct. Test., (2004) 1-9.

[64] V.A. Shutliov, M.E. Alferieff, R.T. Beyer, Fundamental physics of Ultrasound, (1990).

[65] T.S. Awad, H.A. Moharram, O.E. Shaltout, D. Asker, M.M. Youssef, Applications of ultrasound in analysis, processing and quality control of food: A review, Food Res. Int. 48 (2012) 410-427.

[66] J.A. Slotwinski, E.J. Garboczi, K.M. Hebenstreit, Porosity measurements and analysis for metal additive manufacturing process control, J. Res. Natl. Inst. Stand. Technol. 119 (2014) 494. 
[67] G. Juodeikiene, L. Basinskiene, Non-destructive texture analysis of cereal products, Food Res. Int. 37 (2004) 603-610.

[68] I. Akseli, B.C. Hancock, C. Cetinkaya, Non-destructive determination of anisotropic mechanical properties of pharmaceutical solid dosage forms, Int. J. Pharm. 377 (2009) 35-44.

[69] S.P. Simonaho, T.A. Takala, M. Kuosmanen, J. Ketolainen, Ultrasound transmission measurements for tensile strength evaluation of tablets, Int. J. Pharm. 409 (2011) 104110.

[70] J.D. Stephens, M. V. Lakshmaiah, B.R. Kowalczyk, B.C. Hancock, C. Cetinkaya, Wireless transmission of ultrasonic waveforms for monitoring drug tablet properties and defects, Int. J. Pharm. 442 (2013) 35-41.

[71] J.D. Stephens, B.R. Kowalczyk, B.C. Hancock, G. Kaul, C. Cetinkaya, Ultrasonic realtime in-die monitoring of the tablet compaction process - A proof of concept study, Int. J. Pharm. 442 (2013) 20-26.

[72] S.M. Razavi, G. Callegari, G. Drazer, A.M. Cuitino, Toward predicting tensile strength of pharmaceutical tablets by ultrasound measurement in continuous manufacturing, Int. J. Pharm. 507 (2016) 83-89.

[73] M. a Hakulinen, J. Pajander, J. Leskinen, J. Ketolainen, B. van Veen, K. Niinimäki, K. Pirskanen, a Poso, R. Lappalainen, Ultrasound transmission technique as a potential tool for physical evaluation of monolithic matrix tablets., AAPS PharmSciTech. 9 (2008) 267-73.

[74] I. Akseli, S. Iyer, H.P. Lee, A.M. Cuitiño, A quantitative correlation of the effect of density distributions in roller-compacted ribbons on the mechanical properties of tablets using ultrasonics and x-ray tomography., AAPS PharmSciTech. 12 (2011) 834-853.

[75] J. Ketolainen, M. Oksanen, J. Rantala, J. Stor-Pellinen, M. Luukkala, P. Paronen, Photoacoustic evaluation of elasticity and integrity of pharmaceutical tablets, Int. J. Pharm. 125 (1995) 45-53.

[76] I. Akseli, C. Cetinkaya, Air-coupled non-contact mechanical property determination of drug tablets, Int. J. Pharm. 359 (2008) 25-34.

[77] T. Rossing, A Brief History of Acoustics, in: Springer Handb. Acoust., Springer (2007) 9-24.

[78] J.P. McCrory, S.K. Al-Jumaili, D. Crivelli, M.R. Pearson, M.J. Eaton, C.A. Featherston, M. Guagliano, K.M. Holford, R. Pullin, Damage classification in carbon fibre composites using acoustic emission: A comparison of three techniques, Compos. Part B Eng. 68 (2015) 424-430.

[79] C.U. Grosse, M. Ohtsu, Acoustic emission testing, Springer Science \& Business Media, 2008.

[80] C.B. Scruby, An introduction to acoustic emission, J. Phys. E. 20 (1987) 946.

[81] J.P. McCrory, S.K. Al-Jumaili, D. Crivelli, M.R. Pearson, M.J. Eaton, C.A. Featherston, M. Guagliano, K.M. Holford, R. Pullin, Damage classification in carbon fibre composites using acoustic emission: A comparison of three techniques, Compos. Part B Eng. 68 (2015) 424-430.

[82] P. Theobald, B. Zeqiri, J. Avison, Couplants and their influence on AE sensor sensitivity, J. Acoust. Emiss. 26 (2008) 91-97.

[83] R. Unnpórsson, Identifying and Monitoring Evolving AE Sources, Acoust. Emiss. (2012) 75.

[84] P. Ziehl, A. Pollock, Acoustic emission for civil structures, Acoust. Emiss. (2012) 1.

[85] C.E. Davies, K. Fenton, Moisture measurement in free flowing particulate solids using an off-the-shelf capacitance level probe, Chemeca 99 Chem. Eng. Solut. in a Chang. Environ. (1999) 339.

[86] S. Tallon, C.E. Davies, M. Kirkegaard, An acoustic method for in-line particle size 
measurement in flowing bulk solids, Proceedings of the Inst. Mech. Eng. Part E J. Process Mech. Eng. 217 (2003) 33-40.

[87] C.E. Davies, S.J. Tallon, N. Brown, Continuous monitoring of bulk density and particle size in flowable powders and grains, Chem. Eng. Res. Des. 83 (2005) 782-787.

[88] A. Crouter, L. Briens, Monitoring lubricant addition using passive acoustic emissions in a V-blender, Powder Technol. 301 (2016) 1119-1129.

[89] V.S. Dave, H.I. Shahin, S.R. Youngren-Ortiz, M.B. Chougule, R. V. Haware, Emerging technologies for the non-invasive characterization of physical-mechanical properties of tablets, Int. J. Pharm. 532 (2017) 299-312.

[90] C. Ruiz-Carcel, A. Starr, E. Nsugbe, Estimation of powder mass flow rate in a screw feeder using acoustic emissions, Powder Technol. 336 (2018) 122-130.

[91] J.A. Zeitler, P.F. Taday, D. a Newnham, M. Pepper, K.C. Gordon, T. Rades, Terahertz pulsed spectroscopy and imaging in the pharmaceutical setting - a review., J. Pharm. Pharmacol. 59 (2007) 209-223.

[92] F. Ellrich, T. Weinland, D. Molter, J. Jonuscheit, R. Beigang, Compact fiber-coupled terahertz spectroscopy system pumped at $800 \mathrm{~nm}$ wavelength, Rev. Sci. Instrum. 82 (2011) 53102.

[93] D. Markl, P. Wang, C. Ridgway, A.P. Karttunen, M. Chakraborty, P. Bawuah, P. Pääkkönen, P. Gane, J. Ketolainen, K.E. Peiponen, J.A. Zeitler, Characterization of the pore structure of functionalized calcium carbonate tablets by terahertz time-domain spectroscopy and x-ray computed microtomography, J. Pharm. Sci. 106 (2017) 15861595.

[94] P.U. Jepsen, R.H. Jacobsen, S.R. Keiding, Generation and detection of terahertz pulses from biased semiconductor antennas, JOSA B. 13 (1996) 2424-2436.

[95] B. Ferguson, X.-C. Zhang, Materials for terahertz science and technology, Nat. Mater. 1 (2002) 26-33.

[96] C.A. Schmuttenmaer, Exploring dynamics in the far-infrared with terahertz spectroscopy, Chem. Rev. 104 (2004) 1759-1780.

[97] W.L. Chan, J. Deibel, D.M. Mittleman, Imaging with terahertz radiation, Reports Prog. Phys. 70 (2007) 1325.

[98] C. Jansen, S. Wietzke, O. Peters, M. Scheller, N. Vieweg, M. Salhi, N. Krumbholz, C. Jördens, T. Hochrein, M. Koch, Terahertz imaging: applications and perspectives, Appl. Opt. 49 (2010) E48-E57.

[99] J.-F. Roux, F. Garet, J.-L. Coutaz, Principles and applications of THz time domain spectroscopy, in: Phys. Appl. Terahertz Radiat., Springer, 2014: pp. 203-231.

[100] L. Ho, R. Müller, M. Römer, K.C. Gordon, J. Heinämäki, P. Kleinebudde, M. Pepper, T. Rades, Y.C. Shen, C.J. Strachan, Analysis of sustained-release tablet film coats using terahertz pulsed imaging, J. Control. Release. 119 (2007) 253-261.

[101] P.F. Taday, Applications of terahertz spectroscopy to pharmaceutical sciences., Philos. Trans. A. Math. Phys. Eng. Sci. 362 (2004) 351-364.

[102] Y.-C. Shen, Terahertz pulsed spectroscopy and imaging for pharmaceutical applications: a review, Int. J. Pharm. 417 (2011) 48-60.

[103] A.A. Gowen, C. O’Sullivan, C.P. O’Donnell, Terahertz time domain spectroscopy and imaging: Emerging techniques for food process monitoring and quality control, Trends Food Sci. Technol. 25 (2012) 40-46.

[104] J. Qin, Y. Ying, L. Xie, The detection of agricultural products and food using terahertz spectroscopy: a review, Appl. Spectrosc. Rev. 48 (2013) 439-457.

[105] K. Wang, D.-W. Sun, H. Pu, Emerging non-destructive terahertz spectroscopic imaging technique: Principle and applications in the agri-food industry, Trends Food Sci. Technol. 67 (2017) 93-105.

[106] M. Parvathi Devi, S.V. Ravindra, K. Tyagi, D. Singh, R. Khanna, Terahertz pulse 
imaging: A promising non-invasive diagnostic modality, Indian J. Dent. 5 (2014) 39-42.

[107] J. El Haddad, B. Bousquet, L. Canioni, P. Mounaix, Review in terahertz spectral analysis, TrAC - Trends Anal. Chem. 44 (2013) 98-105.

[108] S.S. Prabhu, Chapter 4 - Terahertz Spectroscopy: Advances and Applications, in: Mol. Laser Spectrosc. (2018) 65-85.

[109] M. Naftaly, N. Vieweg, A. Deninger, Industrial applications of terahertz sensing: State of play, Sensors. 19 (2019) 4203.

[110] P. Bawuah, P. Silfsten, T. Ervasti, J. Ketolainen, J.A. Zeitler, K.E. Peiponen, Non-contact weight measurement of flat-faced pharmaceutical tablets using terahertz transmission pulse delay measurements, Int. J. Pharm. 476 (2014) 16-22.

[111] P. Bawuah, A. Pierotic Mendia, P. Silfsten, P. Pääkkönen, T. Ervasti, J. Ketolainen, J.A. Zeitler, K.E. Peiponen, Detection of porosity of pharmaceutical compacts by terahertz radiation transmission and light reflection measurement techniques, Int. J. Pharm. 465 (2014) 70-76.

[112] P. Bawuah, D. Markl, D. Farrell, M. Evans, A. Portieri, A. Anderson, D. Goodwin, R. Lucas, J.A. Zeitler, Terahertz-based porosity measurement of pharmaceutical tablets: A tutorial, J. Infrared, Millimeter, Terahertz Waves. (2020) 1-20.

[113] R. Palermo, R.P. Cogdill, S.M. Short, J.K. Drennen, P.F. Taday, Density mapping and chemical component calibration development of four-component compacts via terahertz pulsed imaging, J. Pharm. Biomed. Anal. 46 (2008) 36-44.

[114] M. Juuti, H. Tuononen, T. Prykäri, V. Kontturi, M. Kuosmanen, E. Alarousu, J. Ketolainen, R. Myllylä, K.E. Peiponen, Optical and terahertz measurement techniques for flat-faced pharmaceutical tablets: a case study of gloss, surface roughness and bulk properties of starch acetate tablets, Meas. Sci. Technol. 20 (2008) 15301.

[115] T. Ervasti, P. Silfsten, J. Ketolainen, K.E. Peiponen, A study on the resolution of a terahertz spectrometer for the assessment of the porosity of pharmaceutical tablets, Appl. Spectrosc. 66 (2012) 319-323.

[116] S. Stranzinger, E. Faulhammer, J. Li, R. Dong, J.G. Khinast, J.A. Zeitler, D. Markl, Measuring bulk density variations in a moving powder bed via terahertz in-line sensing, Powder Technol. 344 (2018) 152-160.

[117] D.M. Pozar, Microwave Engineering, John wiley \& sons , 2011.

[118] R. Wellock, A.D. Walmsley, Applications of microwave spectroscopy in process analysis, Spectroscopy Europe, 16 (2004) 23-26.

[119] J.H. Goh, A. Mason, A.I. Al-Shamma'a, M. Field, M. Shackcloth, P. Browning, Non invasive microwave sensor for the detection of lactic acid in cerebrospinal fluid (CSF), in: J. Phys. Conf. Ser. 307 (2011) 12017.

[120] O. Korostynska, A. Mason, A.I. Al-Shamma'a, Flexible microwave sensors for real-time analysis of water contaminants, J. Electromagn. Waves Appl. 27 (2013) 2075-2089.

[121] M. Ateeq, A. Senouci, H. Al-Nageim, A. Al-Shamma'a, Microwave spectroscopy for the analysis of absorption properties of treated waste rubber aggregates, J. Hazardous, Toxic, Radioact. Waste. 16 (2012) 334-342.

[122] M. Ateeq, S. Wylie, A. Al-Shamma'a, H. Al-Nageim, Microwave spectroscopy: a potential technique to analyse bitumen dielectric and physical properties, Meas. Sci. Technol. 23 (2012) 85503.

[123] R. Blakey, O. Korostynska, A. Mason, A. Al-Shamma'a, Real-time microwave based sensing method for vegetable oil type verification, Procedia Eng. 47 (2012) 623-626.

[124] Agilent, Microwave Dielectric Spectroscopy Workshop: Measure the Difference, (2004) $1-42$.

[125] S.F. Adam, H. Packard, Microwave theory and applications, Prentice-Hall Upper Saddle River, NJ, USA, 1969.

[126] V.M. Karbhari, Non-destructive evaluation (NDE) of polymer matrix composites, 
Elsevier, 2013.

[127] Z. Wu, H. Wang, Microwave Tomography for Industrial Process Imaging: Example Applications and Experimental Results., IEEE Antennas Propag. Mag. 59 (2017) 61-71.

[128] G. Dobmann, Electromagnetic Nondestructive Evaluation (VII), IOS Press, 2006.

[129] S. Trabelsi, A.W. Kraszewski, S.O. Nelson, A microwave method for on-line determination of bulk density and moisture content of particulate materials, IEEE Trans. Instrum. Meas. 47 (1998) 127-132.

[130] N.D. Orloff, J. Obrzut, C.J. Long, T. Lam, P. Kabos, D.R. Novotny, J.C. Booth, J.A. Liddle, Dielectric characterization by microwave cavity perturbation corrected for nonuniform fields, IEEE Trans. Microw. Theory Tech. 62 (2014) 2149-2159.

[131] K. a Bakeev, Process Analytical Technology, 2005.

[132] A.S. El-Hagrasy, M. Delgado-Lopez, J.K. Drennen, A process analytical technology approach to near-infrared process control of pharmaceutical powder blending: Part II: Qualitative near-infrared models for prediction of blend homogeneity, J. Pharm. Sci. 95 (2006) 407-421.

[133] H. Choi, J. Naylon, S. Luzio, J. Beutler, J. Birchall, C. Martin, A. Porch, Design and in vitro interference test of microwave noninvasive blood glucose monitoring sensor, IEEE Trans. Microw. Theory Tech. 63 (2015) 3016-3025.

[134] A. Bababjanyan, H. Melikyan, S. Kim, J. Kim, K. Lee, B. Friedman, Real-time noninvasive measurement of glucose concentration using a microwave biosensor, $\mathrm{J}$. Sensors. 2010 (2010).

[135] S.R. Wylie, A. Shaw, A.I. Al-Shamma'a, RF sensor for multiphase flow measurement through an oil pipeline, Meas. Sci. Technol. 17 (2006) 2141.

[136] J.B. Hasted, Aqueous dielectrics, Chapman and Hall, 1973.

[137] S. Trabelsi, A.M. Paz, S.O. Nelson, Microwave dielectric method for the rapid, nondestructive determination of bulk density and moisture content of peanut hull pellets, Biosyst. Eng. 115 (2013) 332-338.

[138] S. Trabelsi, S.O. Nelson, Nondestructive sensing of physical properties of granular materials by microwave permittivity measurement, IEEE Trans. Instrum. Meas. 55 (2006) 953-963.

[139] J. Austin, M.T. Harris, In-situ monitoring of the bulk density and the moisture content of rapidly flowing particulates using a microwave resonance sensor, IEEE Sens. J. 14 (2014) 821-828.

[140] A.W. Kraszewski, S. Trabelsi, S.O. Nelson, Wheat permittivity measurements in free space, J. Microw. Power Electromagn. Energy. 31 (1996) 135-141.

[141] S.O. Nelson, Measurement of microwave dielectric properties of particulate materials, J. Food Eng. 21 (1994) 365-384.

[142] S.O. Nelson, Agricultural applications of dielectric measurements, IEEE Trans. Dielectr. Electr. Insul. 13 (2006) 688-702.

[143] W. Meyer, W. Schilz, A microwave method for density independent determination of the moisture content of solids, J. Phys. D. Appl. Phys. 13 (1980) 1823.

[144] A.D. Dane, G.J. Rea, A.D. Walmsley, S.J. Haswell, The determination of moisture in tobacco by guided microwave spectroscopy and multivariate calibration, Anal. Chim. Acta. 429 (2001) 185-194.

[145] M. Kent, R. Knöchel, F. Daschner, U.-K. Berger, Composition of foods including added water using microwave dielectric spectra, Food Control. 12 (2001) 467-482.

[146] Y. Zhang, Y. Ogura, Density-independent high moisture content measurement using phase shifts at two microwave frequencies, J. Microw. Power Electromagn. Energy. 44 (2010) 163-167.

[147] C. Buschmüller, W. Wiedey, C. Döscher, J. Dressler, J. Breitkreutz, In-line monitoring of granule moisture in fluidized-bed dryers using microwave resonance technology, Eur. 
J. Pharm. Biopharm. 69 (2008) 380-387.

[148] S. Watano, K. Terashita, K. Miyanami, Development and application of infrared moisture sensor to complex granulation, Bulletin of University of Osaka Prefecture. Series A, Engineering and Natural Sciences 39 (1991) 187-197.

[149] J.G. White, On-line moisture detection for a microwave vacuum dryer, Pharm. Res. 11 (1994) 728-732.

[150] J. Rantanen, S. Lehtola, P. Rämet, J.-P. Mannermaa, J. Yliruusi, On-line monitoring of moisture content in an instrumented fluidized bed granulator with a multi-channel NIR moisture sensor, Powder Technol. 99 (1998) 163-170.

[151] J. Peters, W. Taute, K. Bartscher, C. Döscher, M. Höft, R. Knöchel, J. Breitkreutz, Design, development and method validation of a novel multi-resonance microwave sensor for moisture measurement, Anal. Chim. Acta. 961 (2017) 119-127.

[152] M.G. Rasteiro, R. Silva, F.A.P. Garcia, P. Faia, Electrical tomography: A review of configurations and applications to particulate processes, KONA Powder Part. J. 29 (2011) 67-80.

[153] M.S. Beck, M. Byars, T. Dyakowski, R. Waterfall, R. He, S.J. Wang, W.Q. Yang, Principles and industrial applications of electrical capacitance tomography, Meas. Control. 30 (1997) 197-200.

[154] W. Daily, A. Ramirez, A. Binley, D. LaBrecque, Electrical resistance tomographyTheory and practice, in: Near-Surface Geophys., Society of Exploration Geophysicists, (2005) 525-550.

[155] A. Arko, R.C. Waterfall, M.S. Beck, T. Dyakowski, P. Sutcliffe, M. Byars, Development of electrical capacitance tomography for solids mass flow measurement and control of pneumatic conveying systems, in: 1st World Congr. Ind. Process Tomogr. Buxton, Gt. Manchester (1999) 14-17.

[156] W.Q. Yang, T. a. York, New AC-based capacitance tomography system, IEE Proc. - Sci. Meas. Technol. 146 (1999) 47.

[157] W.Q. Yang, L. Peng, Image reconstruction algorithms for electrical capacitance tomography, Meas. Sci. Technol. 14 (2002) R1.

[158] N. a Valous, D.-W. Sun, 4 - Image processing techniques for computer vision in the food and beverage industries, Woodhead Publishing Limited, 2012.

[159] R. Mann, F.J. Dickin, M. Wang, T. Dyakowski, R.A. Williams, R.B. Edwards, A.E. Forrest, P.J. Holden, Application of electrical resistance tomography to interrogate mixing processes at plant scale, Chem. Eng. Sci. 52 (1997) 2087-2097.

[160] G.T. Bolton, K.M. Primrose, An overview of electrical tomographic measurements in pharmaceutical and related application areas., AAPS PharmSciTech. 6 (2005) E137E143.

[161] M. Sharifi, B. Young, Electrical resistance tomography (ERT) applications to chemical engineering, Chem. Eng. Res. Des. 91 (2013) 1625-1645.

[162] C.G. Xie, S.M. Huang, C.P. Lenn, A.L. Stott, M.S. Beck, Experimental evaluation of capacitance tomographic flow imaging systems using physical models, IEE Proc. Circuits, Devices Syst. 141 (1994) 357-358.

[163] S.M. Huang, A.B. Plaskowski, C.G. Xie, M.S. Beck, Tomographic imaging of twocomponent flow using capacitance sensors, J. Phys. E. 22 (1989) 173.

[164] B.J. Azzopardi, K. Jackson, J.P. Robinson, R. Kaji, M. Byars, A. Hunt, Fluctuations in dense phase pneumatic conveying of pulverised coal measured using electrical capacitance tomography, Chem. Eng. Sci. 63 (2008) 2548-2558.

[165] T. Dyakowski, S.P.P. Luke, K.L.L. Ostrowski, R.R. a. Williams, On-line monitoring of dense phase flow using real time dielectric imaging, Powder Technol. 104 (1999) 287295.

[166] A.J. Jaworski, T. Dyakowski, Investigations of f low instabilities within the dense 
pneumatic conveying system, Powder Technol. 125 (2002) 279-291.

[167] C. Yang, Z. Cui, Q. Xue, H. Wang, D. Zhang, Y. Geng, Application of a high speed ECT system to online monitoring of pneumatic conveying process, Meas. J. Int. Meas. Confed. 48 (2014) 29-42.

[168] C. Nied, J.A. Lindner, K. Sommer, On the influence of the wall friction coefficient on void fraction gradients in horizontal pneumatic plug conveying measured by electrical capacitance tomography, Powder Technol. 321 (2017) 310-317.

[169] W. Zhang, C. Wang, W. Yang, C.-H. Wang, Application of electrical capacitance tomography in particulate process measurement - A review, Adv. Powder Technol. 25 (2014) 174-188.

[170] S. Liu, Q. Chen, H.G. Wang, F. Jiang, I. Ismail, W.Q. Yang, Electrical capacitance tomography for gas-solids flow measurement for circulating fluidized beds, Flow Meas. Instrum. 16 (2005) 135-144.

[171] N. Ehrhardt, M. Montagne, H. Berthiaux, B. Dalloz-Dubrujeaud, C. Gatumel, Assessing the homogeneity of powder mixtures by on-line electrical capacitance, Chem. Eng. Process. Process Intensif. 44 (2005) 303-313.

[172] V. Rimpiläinen, S. Poutiainen, L.M. Heikkinen, T. Savolainen, M. Vauhkonen, J. Ketolainen, Electrical capacitance tomography as a monitoring tool for high-shear mixing and granulation, Chem. Eng. Sci. 66 (2011) 4090-4100.

[173] T. Dyakowski, L.F.C. Jeanmeure, A.J. Jaworski, Applications of electrical tomography for gas-solids and liquid- solids flows - a review, Powder Technol. 112 (2000) 174-192.

[174] J. Yao, M. Takei, Application of Process Tomography to Multiphase Flow Measurement in Industrial and Biomedical Fields - A Review, IEEE Sens. J. 17 (2017) 8196-8205.

[175] F. Ricard, C. Brechtelsbauer, X.Y. Xu, C.J. Lawrence, Monitoring of multiphase pharmaceutical processes using electrical resistance tomography, Chem. Eng. Res. Des. 83 (2005) 794-805.

[176] Novelline, Robert, R. Novelline, Squire's Fundamentals of Radiology, Harvard University Press, 1997.

[177] J.A. Seibert, X-ray imaging physics for nuclear medicine technologists. Part 1: Basic principles of X-ray production, J. Nucl. Med. Technol. 32 (2004) 139-147.

[178] A.C. Thompson, D. Vaughan, X-ray data booklet, Lawrence Berkeley National Laboratory, University of California Berkeley, CA, 2001.

[179] P. Russo, 2.01 - Physical Basis of x-Ray Imaging, in: Compr. Biomed. Phys., Elsevier, Oxford (2014) 1-48.

[180] L. Farber, G. Tardos, J.N. Michaels, Use of X-ray tomography to study the porosity and morphology of granules, Powder Technol. 132 (2003) 57-63.

[181] R. Wiedey, P. Kleinebudde, Infrared thermography - A new approach for in-line density measurement of ribbons produced from roll compaction, Powder Technol. 337 (2018) $17-24$.

[182] R. Van Grieken, A. Markowicz, Handbook of X-ray Spectrometry, CRC press, 2001.

[183] W. Cao, M.P. Mullarney, B.C. Hancock, S. Bates, K.R. Morris, Modeling of transmitted $\mathrm{X}$-ray intensity variation with sample thickness and solid fraction in glycine compacts, $\mathrm{J}$. Pharm. Sci. 92 (2003) 2345-2353.

[184] B.C. Hancock, M.P. Mullarney, X-ray microtomography of solid dosage forms, Pharm. Technol. 29 (2005) 92-100.

[185] J.A. Zeitler, L.F. Gladden, In-vitro tomography and non-destructive imaging at depth of pharmaceutical solid dosage forms, Eur. J. Pharm. Biopharm. 71 (2009) 2-22.

[186] S.R. Stock, X-ray microtomography of materials, Int. Mater. Rev. 44 (1999) 141-164.

[187] P.-J. Liotier, V. Alain, D. Christine, Characterization of 3D morphology and microcracks in composites reinforced by multi-axial multi-ply stitched preforms, Compos. Part A Appl. Sci. Manuf. 41 (2010) 653-662. 
[188] F. Desplentere, S. V Lomov, D.L. Woerdeman, I. Verpoest, M. Wevers, A. Bogdanovich, Micro-CT characterization of variability in 3D textile architecture, Compos. Sci. Technol. 65 (2005) 1920-1930.

[189] L.P. Djukic, I. Herszberg, W.R. Walsh, G.A. Schoeppner, B.G. Prusty, D.W. Kelly, Contrast enhancement in visualisation of woven composite tow architecture using a MicroCT Scanner. Part 1: Fabric coating and resin additives, Compos. Part A Appl. Sci. Manuf. 40 (2009) 553-565.

[190] L.P. Djukic, I. Herszberg, W.R. Walsh, G.A. Schoeppner, B.G. Prusty, Contrast enhancement in visualisation of woven composite architecture using a MicroCT Scanner. Part 2: Tow and preform coatings, Compos. Part A Appl. Sci. Manuf. 40 (2009) 18701879.

[191] E. Padilla, N. Chawla, L.F. Silva, V.R. Dos Santos, S. Paciornik, Image analysis of cracks in the weld metal of a wet welded steel joint by three dimensional (3D) X-ray microtomography, Mater. Charact. 83 (2013) 139-144.

[192] M.S. Nielsen, T. Lauridsen, L.B. Christensen, R. Feidenhans, X-ray dark-field imaging for detection of foreign bodies in food, Food Control. 30 (2013) 531-535.

[193] B. Wagner, T. Brinz, J. Khinast, Using online content uniformity measurements for rapid automated process development exemplified via an X-ray system, Pharm. Dev. Technol. 24 (2019) 775-787.

[194] I.C. Sinka, S.F. Burch, J.H. Tweed, J.C. Cunningham, Measurement of density variations in tablets using X-ray computed tomography, Int. J. Pharm. 271 (2004) 215-224.

[195] C. Pei, H. Lin, D. Markl, Y.-C. Shen, J.A. Zeitler, J.A. Elliott, A quantitative comparison of in-line coating thickness distributions obtained from a pharmaceutical tablet mixing process using discrete element method and terahertz pulsed imaging, Chem. Eng. Sci. 192 (2018) 34-45. 